\title{
Numerical comparison of two operating modes of thermal energy storage tank for compression heat storage in adiabatic compressed air energy storage
}

\author{
Chidiebere Diyoke ${ }^{a} b^{*}$, Ugochukwu Ngwaka ${ }^{c}$ \\ a School of Engineering, University of Hull, Hull, UK, HU6 7RX. \\ ${ }^{\mathrm{b}}$ Faculty of Engineering, Enugu State University of Science and Technology (ESUT) \\ PMB 01660. Agbani, Enugu State, Nigeria \\ c School of Engineering, Newcastle University, Newcastle upon Tyne NE1 7RU, UK
}

Mobile: +234-803-445-8808; E-mail: chidiebere.diyoke@esut.edu.ng (C Diyoke)

\begin{abstract}
Two different charging modes of a thermal energy storage tank system employing multi-phase change material for compression heat storage in an adiabatic compressed air energy storage process was simulated to compare their performance. The modes are mod1 with higher mass flow rate and low temperature and mod 2 with higher temperature and low mass flow rate of heat transfer fluid respectively. A mathematical formulation of the energy interactions in the HTF and the PCM filling the TEST was discretized using implicit finite difference technique and solved in Matlab using a matrix inversion technique. The developed model showed good agreement with experimental data of temperature profile of heat transfer fluid during the charging mode. The two modes were compared using metrics such as charging rate, discharging rate, charging efficiency, discharging efficiency, charging and discharging exergy efficiency, and overall exergy and energy efficiency. It was found that mod 2 performs better than mod 1 in both the charging and discharging cycle. The round trip efficiency of mod 1 ranges from 0.87 to 0.77 with a mean value of 0.76 whereas that for mod 2 ranged from 0.97 to 0.79 with an average of 0.78 . Moreover, the overall exergy efficiency ranges from a peak value of 0.48 and 0.55 to the least value of 0.33 and 0.44 in mod 1 and mod 2 respectively, corresponding to average efficiencies of 0.45 and 0.51 in $\bmod 1$ and $\bmod 2$ respectively. The numerical results offer guidance for the selection of the appropriate mode.
\end{abstract}

Key words: Wind energy storage; Numerical modelling; Latent heat storage; Renewable energy; Phase change material. 


\section{Highlights}

Thermal performance of multi-PCM TES tank is numerically analysed.

A numerical model is used for thermal comparison of two charging configurations.

A parametric study of PCM packing height is performed.

Results indicate that correct arrangement of PCM packing height is critical. 


\section{Introduction}

Rapid globalization, invention, and population growth have brought about an incessant increase in annual energy demand, mainly satisfied by centralised fossil fuel-powered generation. However, the depleting characteristic of fossil fuels and the mounting global warming problem, resulting mainly from fossil fuel combustion, has inspired growing global commitment towards the usage of renewable energy (RE) resources [1-3] for supplying worldwide energy requirements. Apart from the use of RE sources, researchers [4-6] have also proposed several thermodynamic cycles to relieve such issues including organic Rankine cycle(ORC), Kalina cycle, supercritical $\mathrm{CO}_{2}$ cycle, triangle cycle, and heat pipe technology.

Among many RE sources such as wind, biomass, hydropower, geothermal power, solar, hydrogen and fuel cells; wind-based power has emerged as one of the potential renewable energy sources to lead the charge in the transition away from the use of fossil fuel in energy generation [7]. This is because of its wide availability and free nature. However, wind energy source has a variable nature, which makes it challenging to match demand with supply. This creates limitations for wind-based power applications. Wind power in amalgamation with energy storage (ES) has been acknowledged as a key solution to smoothen out the variability and ensure that wind generation matches the demand. Consequently, wind-based energy storage technologies have continued to rouse more attention.

Adiabatic Compressed Air Energy Storage (A-CAES) is one of the many energy storage technologies that have a very prominent role to play in wind power applications [8]. In the charging mode of an A-CAES process, electricity is deployed to power compressors to compress air. The thermal energy contained in the pressurised compressed air (CA) exiting the compressors is then recuperated and stored in thermal energy storage (TES) media. During discharging mode, the stored thermal energy is recovered to reproduce the electricity in an air expander. The efficiency of the transformation of the electrical energy to thermal energy and back to electrical energy in the A-CAES process is governed by laws of thermodynamics. By these laws, it is not possible to transform all the electricity to heat during the charging phase and reconvert all the stored heat back to electricity during the discharging phase. These limitations can be quantified by a Carnot efficiency related to a theoretical cycle generating electricity from heat delivered at a constant (high) temperature $\left(\mathrm{T}_{\mathrm{HTF}, \mathrm{in}}\right)$ and released at a constant (low) temperature ( $\left.\mathrm{T}_{\mathrm{TEST}, \text { init }}\right)$, given as:

$$
\mathrm{P}_{\text {output }}=\left(1-\left(\mathrm{T}_{\mathrm{TEST}, \text { init }} / \mathrm{T}_{\mathrm{HTF}, \mathrm{in}}\right)\right) \times \text { Power }_{\text {input }}
$$

From the above expression, it is obvious that the greater the temperature of the HTF, the greater the heat that will be supplied to the TES medium at a high-temperature level and the greater the overall performance.

In an A-CAES process, the temperature of the HTF entering the TES tank is the compressor exit temperature. To achieve an entry temperature to the thermal energy storage tank (TEST) that is greater than the exit temperature from the compressor, an electrical heater is a potential subsystem that can be integrated into the A-CAES system so that some part of the excess wind electricity can be used to further preheat the air post-compression from the air compressor before entering the TEST. This will increase the temperature of the CA delivered to the TEST. However, this comes with a penalty of a decreased mass flow rate of pressurized CA entering the TEST. 
Numerous researchers [9-17], have studied the effect of temperature and mass flow rate respectively on the thermal performance of a latent heat (LH) TEST and have established that the charging and discharging performance of the LH TEST system improves as the temperature or mass flow rate of the HTF rises $[11-13,15]$. Since both air mass flow rate $\left(\dot{m}_{f}\right)$ and temperature (T) affect the performance of an LH TEST, what then happens when the inlet HTF temperature is increased and the mass flow rate reduced simultaneously in the same charging process? To answer that question, two modes of operation of a TEST for the A-CAES process is investigated in this research. The modes are mod1 with higher mass flow rate $\left(\mathrm{m}_{\mathrm{f}}\right)$ and low temperature $(\mathrm{T})$ and mod2 with higher temperature and low mass flow rate of HTF respectively.

Some work exists in the published literature relating to modeling and simulation of thermal energy storage in packed beds for the A-CAES application. Peng et al. [12] numerically modelled the thermal performance of compressed air in a packed bed system using phase change material (PCM) particle filler. They reported that the charge efficiency rises with a rise in inlet pressure of CA.

Barbour et al. [18] numerically simulated an A-CAES with sensible heat packed bed TES. They reported that the efficiency of more than $70 \%$ could be achieved by the system. In continuance of their study, an exergy analysis carried out indicated that the main losses occur in the compressors and expanders (accounting for approximately $20 \%$ of the work input) and not in the packed beds.

In another study, Tessier et al. [19] studied an exergy analysis of an A-CAES employing a cascade of four PCMs as TES mediums. They reported that thermal storage and recovery efficiencies could be as high as $85 \%$ representing a $15 \%$ increase over A-CAES using sensible heat TES.

Apart from the subject area of A-CAES, a good number of mathematical models have been reported in the literature for calculating the thermal performance of a LH TES system. Mohammed Raddy [20] carried out an experiment and numerical simulations of using granular phase change materials for thermal energy storage. Comparisons between experimental and numerical results were adopted to evaluate the sensitivity of numerical simulations to different model parameters such as effects of phase change characteristics, effects of bed porosity and effects of fluid-to-particle heat transfer coefficient and axial dispersion. Xia et al. [21] numerically developed and validated an effective packed bed model that could investigate the heat transfer behaviour of packed bed latent heat storage systems. The results indicated that random PCM packing is better for heat storage and retrieval when compared to special packing. In another study, the dynamic performances of a solar heat storage system with a packed bed using myristic acid as phase change material was numerically studied by Wu and Fang [17]. The effects of inlet temperature, flow rate and initial temperatures of HTF and PCM on heat release rate and the latent efficiency are also analysed and discussed. Karthikeyan and Velraj [22] carried out a comparative numerical investigation of three different mathematical models for packed bed latent heat storage systems. The result suggests that one model is preferred when air is the HTF while another model is recommended when water is the HTF. Amin et al. [23] presented the results of a parametric study using an experimentally validated numerical model for PCM encapsulated in plates. Zhao et al. [24] conducted a transient two-dimensional heat transfer analysis to investigate high-temperature energy storage using encapsulated phase change materials for concentrated solar power applications. Numerical simulations were done by employing a front-tracking and an enthalpy-porosity method. It was reported that the results 
predicted by the two methods strongly agree. A Numerical model was proposed by Al-Abidi et al. [25] to investigate PCM solidification in a triplex tube heat exchanger with internal and external fins. Experiments were also carried out to validate the proposed model. It was reported that simulation results agreed with the experimental results. Peng et al. [26] also numerically studied the thermal behaviour of a PCM-based high-temperature thermal energy storage in a packed bed. The results obtained are validated with experimental results from the literature. The impacts of PCM capsule diameter, fluid inlet velocity, and height of storage tank on the temperature histories of the packed bed are presented and discussed. They reported that a decrease in the size of PCM capsule and fluid inlet velocity, or an increase in the storage height, increases the charge efficiency. In a related study, Wu et al., [27] carried out a dynamic thermal performance analysis of a molten-salt packed-bed thermal energy storage system using PCM capsules. A transient two-dimensional dispersion-concentric model is modified to account for the phase change process within the capsules. Using the model, detailed characteristics of heat transfer between molten salt and the packed PCM capsules are investigated, and a parametric sensitivity analysis is provided. It was found that the effective discharging efficiency of the system can be increased by decreasing the molten-salt inlet velocity or decreasing the capsule diameter. Aldoss and Rahman [28] carried out a comparison between the single-PCM and multi-PCM thermal energy storage design. The results suggest that as the number of stages increases, the multi-PCM thermal energy storage (TES) performance increases. However, the use of more than three stages does not add any significant enhancement in the system performance. Also, Bellan et al. [29] carried out numerical and experimental studies on heat transfer characteristics of a thermal energy storage system packed with molten salt PCM capsules. The results indicated that the Stefan number plays a vital role in the total heat storage capacity due to sensible heat and the shell properties of the capsule significantly impact the thermal performance of the system. Izquierdo-Barrientos et al. [30] presented a numerical and experimental study of the transient response of a TES tank filled with a granular PCM. It was reported that the numerical and experimental heating results exhibited good agreement, and the stored energy in the wall of the TES tank represents between 8 and 16\% of the total energy stored in the PCM. Bhagat and Saha [16] presented a numerical study on the transient response of packed bed latent heat (LH) TES system in eliminating variations in the HTF temperature in the charging and discharging period. The enthalpy method was used to account for phase change in PCM. It was reported that the energy-storing and releasing ability of the LH TES system is significantly improved by increasing mass flow rate and inlet charging temperature. In a similar study by Dadollahi and Mehrpooya [31], the charging process of high-temperature PCMs in three different TES tank configurations was modelled numerically. They reported that the ratio of surface area to volume of the PCM domain plays a significant role in charging time and an increase in HTF velocity leads to a decrease in charging time but not always.

Pakrouh et al.[32] numerically studied the thermodynamic performance of a packed bed LH TES system using an effective packed bed model. The results suggest that both a decrease in capsules' diameter and the HTF inlet temperature unfavourably leads to a rise in the amount of irreversibility in the system. Nonetheless, it was established that the increase in the irreversibility does not result in a decrease in performance of the LH TES system. Li et al., [13] experimentally and numerically studied the performance of a new high temperature packedbed thermal energy storage system with macro encapsulation of molten salt phase change material. The results show that the increase of inlet temperature and mass flow rate in parked bed TES can increase its charging and discharging efficiencies. Pirasaci et al. [33] developed a numerical thermal model for the design of a latent heat storage unit with air as the heat transfer fluid. The results were validated against experimental data from the literature. It was reported that decreasing the number of capsules and the distance between capsules also decreases the 
operation time. However, the decrease in the flow rate increases the operation time. Wang et al. [34] performed an experimental and modelling study on the thermal performance of hydrated salt latent heat thermal energy storage system. It was found that the heat transfer between thermal fluid and PCM relied greatly on the geometry of the storage tube and fins attribution. Mehta et al. [35] carried out an experimental comparative thermal performance assessment for vertical and horizontal orientation of shell and tube type LH TES Unit. The results suggest that horizontal orientation is better for part-load operation as compared to a vertical orientation, as it requires lesser time to melt half of the PCM mass. Khan and Khan [36] carried out a thermodynamic performance of a novel shell-and-tube heat exchanger incorporating paraffin as a thermal storage solution for domestic and commercial applications. It was reported that the average charging and discharging powers are enhanced significantly by $75.53 \%$ and $27.04 \%$ respectively, with a rise in the temperature gradient between PCM and HTF from $52{ }^{\circ} \mathrm{C}$ to $62{ }^{\circ} \mathrm{C}$ and $15^{\circ} \mathrm{C}-5^{\circ} \mathrm{C}$, respectively. Lee et al. [37] performed a numerical analysis of a full-scale thermal energy storage tank with a dual PCM capsule. A single tank for both heating and cooling modes was considered for this study. The tank was filled with coolingPCM or heating-PCM. The results suggest that the combined ratio in the dual PCM tank is within a 50/50 - 90/10 mixing zone ratio, of the cooling-PCM/heating-PCM respectively. Mao and Zhang [38] studied the thermal energy storage performance of a 3-PCM cascade tank in a high-temperature packed bed system. A model based on a concentric-dispersion model and the enthalpy method was used to analyse the phase transition of the PCM. The result suggests that the storage capacity and utilisation rate of 3-PCM energy storage tanks are relatively high and that the shape of the tank has no effect on the storage capacity at a fixed tank volume. Guerraiche et al.[39] implemented an experimental and numerical study of a solar collector using phase change material as heat storage. It was found that the phase change material showed good heat retention of 2 hours to 1 hour 40 minutes for water inlet temperature $30^{\circ} \mathrm{C}$ and $40^{\circ} \mathrm{C}$ respectively. Thermal performance optimization and evaluation of a radial finned shell-and-tube latent heat thermal energy storage unit were carried out by $\mathrm{Pu}$ et al. [40]. The results show that the complete melting time could be reduced by $49.9 \%$ by arithmetic fins. In a related study, Ahmed et al. [41] implemented a thermal performance analysis of thermocline combined sensible-latent heat storage system using cascaded-layered PCM designs for medium temperature applications. It was reported that the use of multistage PCMs with the appropriate combination of layer thickness and fusion temperature together with the inclusion of cheaper structured filler material, offers an efficient and cost-effective TES alternative.

From the literature reviewed so far, it is obvious that modelling LH TEST has been studied extensively over the years but no research currently in public domain exists that compares the two modes proposed in the present work. Although the influence of temperature or mass flow rate on the performance of an LH TES system has been studied by many researchers $[11,12]$, these studies have been carried out by varying one quantity and keeping the other constant. The novelty of this lies on the fact that no other study has been carried out for a case where both quantities $\left(\dot{m}_{\mathrm{f}}, \mathrm{T}\right)$ vary inversely with each other like in the two charging modes. Hence there is the need to investigate the thermal performance of the two alternative charging modes of a PCM based TES system for A-CAES application to know the operating characteristics of the two modes and which is better option between them and why?

Consequently, a transient two-dimensional concentric dispersion model (CDM) of a TEST system employing multiple encapsulated PCM is developed in this study to reveal the thermal response of the TEST for the two operational modes. The CDM is used because it allows for the solution of the temperature distribution inside the solid particles. The performance of the two modes is analysed using stored energy, charging and discharging temperature profile, 
energy efficiency, and exergy efficiency. Also, the impact of capsule arrangement on the performance of the two modes are appraised. The current work can show insight as well as offer guidance for the selection of the appropriate operating mode for the A-CAES application.

\subsection{System Description}

\subsection{Description of the two modes}

Fig. 1 depicts the typical diagram of the A-CAES system, consisting of air compressor (AC), thermal energy storage tank (TEST), air store (AS) and air Turbine (AT). The temperature and mass flow rate of air exiting the compression system forms the input HTF to the TEST. Based on the temperature and mass flow rate of compressed air entering the TEST, the A-CAES system can be operated in two different modes during the charging process. The two modes are referred to as mode $1(\bmod 1)$ and mode $2(\bmod 2)$ respectively.

Mod1: This mode is the conventional operating mode of the A-CAES system. During the charging cycle, the entire electricity of the wind turbine $\left(W_{W T}\right)$ is deployed to drive the compressor to compress air and the thermal energy contained in the high pressurised CA exiting the AC is absorbed and stored in the TEST. For a constant stage pressure ratio and ambient conditions, the electrical power input to the compressor determines the mass flow rate of CA exiting the compressor while the number of stages determines the temperature of the HTF. The higher the temperature and/or mass flow rate of the compressed air entering the TEST, the better will be the effectiveness of the storage/retrieval of thermal energy to/from the TEST.

Mod2: The main difference between $\bmod 2$ and $\bmod 1$ is that in $\bmod 2$, the charging process of the A-CAES system is split into two stages: in the first stage, some of the wind turbine power $\left(W_{W T}-\psi W_{W T}\right)$ is used to drive a compressor to compress air to a particular temperature; the second stage involves using the remaining part of the wind turbine power $\left(\psi W_{W T}\right)$ to operate an electric filament to heat the hot $\mathrm{CA}$ exiting the $\mathrm{AC}$ to a higher temperature, before it enters the TEST. Although mode2 leads to a higher CA inlet temperature to the TEST, since power input to the compressor is lower in this mode, it, however, comes with a penalty of reduction in the mass flow rate of the CA exiting the compressor and entering the TEST.

Having identified the two operating modes: mod1 with higher mass flow rate $(\dot{m})$ and low temperature (T) and mod 2 with higher temperature and low mass flow rate, it is necessary to evaluate them to provide an answer to the question; of the two operating modes which one is better and why?

The proposed A-CAES system compression and TES system are targeted to large size CAES plant capable of absorbing excess electric power from the grid in the megawatt range. The design storage pressures for such capacities can range from 40 to about 100 bar $[42,43]$. Depending on the overall pressure ratio, so many different kinds of compressors have been considered by different authors in their studies related to A-ACAES [44]. 


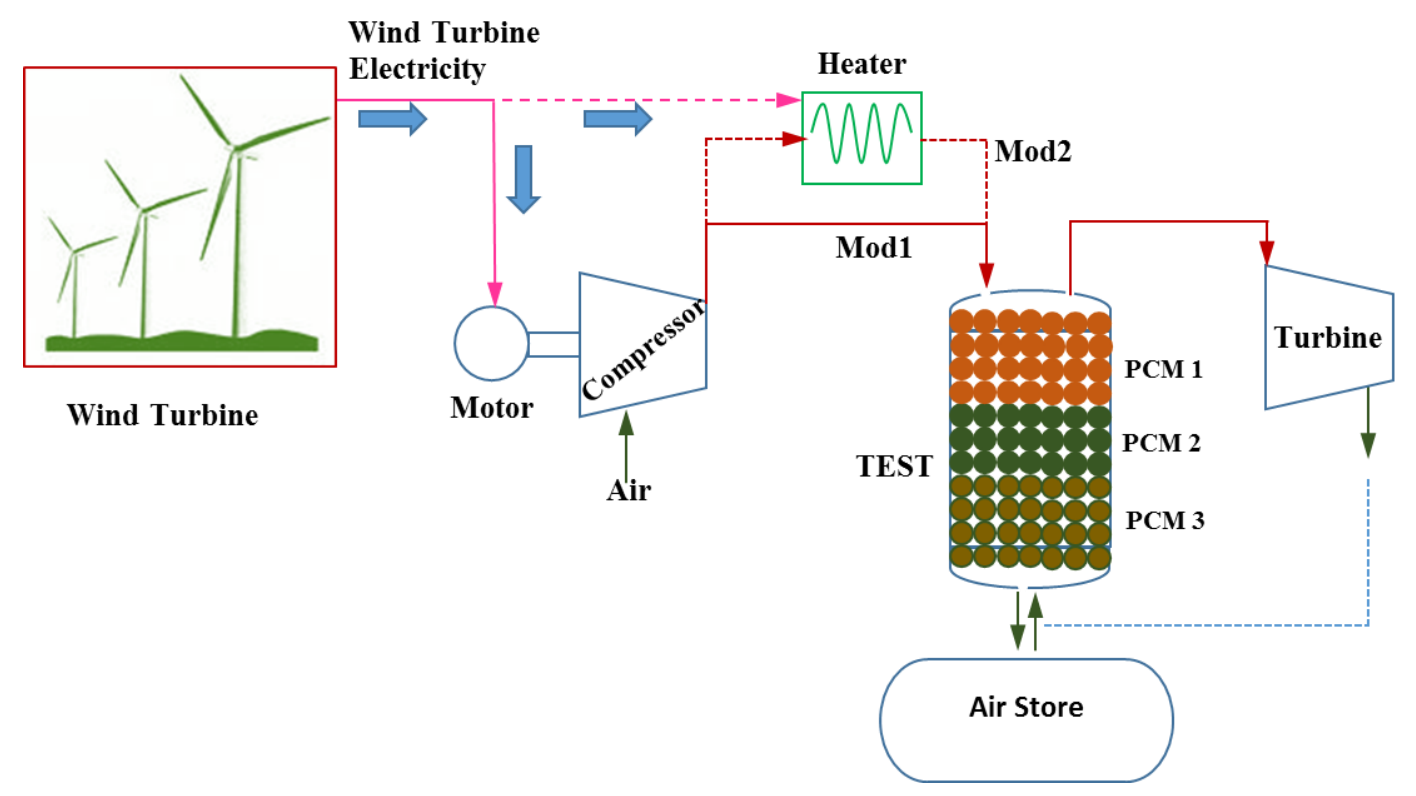

Figure 1: Schematic of TEST showing two charging modes

To minimise the work required to achieve a given storage pressure, each compression stage usually has an equal pressure ratio. Budt et al. [42], Zhao et al [45] and Hartmann et al [46] used equal pressure ratio in the analysis of A-CAES with two compressor and turbine configurations. In the present analysis, for a hypothetical excess wind power capacity of 20 MW and overall compressor pressure ratio of 64, a two-stage centrifugal compressor connected in series and having equal pressure ratio per stage is considered. The justification for the choice made above include:

1. To keep the outlet temperature within the allowable temperature of the compressor material. This allows the applicability of off-the-shelf compression and expansion devices. Currently, available turbo compressors are limited to outlet temperatures far below $600{ }^{\circ} \mathrm{C}[42,47,48]$

2. To avoid some technical challenges associated with operating TES at a comparatively high temperature of more than $400{ }^{\circ} \mathrm{C}$. Such technical challenges are enumerated in [47] and not repeated here for want of space.

3. The two stage configuration shows better part-load efficiencies and less storage losses [47]. It is adjudged by the authors [46,49] to be the best when systematic complexity and system performance are comprehensively considered.

Having identified the two operating modes: mod1 with higher mass flow rate $\left(\mathrm{m}_{\mathrm{f}}\right)$ and low temperature (T) and mod2 with higher temperature and low mass flow rate, it is necessary to evaluate them to provide an answer to the question; of the two operating modes which one is better and why?

\subsection{Description of the PCM based TES tank unit}

The TEST is made of a cylindrical steel tank which has a thermal conductivity of $16.0 \mathrm{Wm}^{-1} \mathrm{~K}$, a density of $7920 \mathrm{kgm}^{-3}$ and a specific heat of $499 \mathrm{Jkg}^{-1} \mathrm{~K}$ [50]. Its height and diameter are $10 \mathrm{~mm}$ and $6 \mathrm{~mm}$, respectively. The whole surface of the TES tank is covered with $0.05 \mathrm{~m}$ thickness of glass wool insulation and an outer covering of $0.001 \mathrm{~m}$ thickness of steel plate 
[51]. The TEST is divided into three sections and filled with three different encapsulated phase change materials (PCMs) referred to hereafter as PCM1, PCM2, and PCM3, respectively.

\subsection{Selection of PCMs}

There are two different types of PCMs such organic compounds and inorganic salts with their eutectics salts [52-56]. The organic PCM consists of paraffin and non-paraffin PCM. Inorganic PCM include salts, salt hydrates and metals and alloys. A good number of research has been conducted on using the different kinds of PCM for LH TES [24,26,27,29,54]. Each type of PCM has their own advantages and limitations, hence the selection of a particular type of PCM has to be done by considering the requirements of a given application. Ultimately, the selected PCM should have melting temperature within the practical range of application [57].

Inorganic PCMs have more latent heat and thermal conductivity with sharp melting point, but with inferior corrosion resistance and weaker thermal stability compared to Organic PCMs, that have very low corrosion, high heat of fusion and much better thermal/chemical stability, but with a much lower latent heat and thermal conductivity [54,58]. Inorganic PCMs are also linked with disadvantages such as materials degradation, segregation and super cooling [52,58]. Generally, most PCMs have corrosion, sub cooling, low thermal conductivity and leakage issues [52]. A detailed explanation of all the issues of the different types of PCMs and their solutions are described in Li et al's publications [52,53].

Organic PCMs commonly have low melting points and can only be applied in room-heating thermal storage. For high temperature LH TES, molten salts have been extensively studied by researchers [54] (Xu et al., 2015). When the application involves medium to high temperature heat sources like in solar salts, compressed air energy storage, nitrate and nitrite salt phase change materials have been widely investigated [54]. Hence, in the current study, inorganic PCMs was selected because their melting temperature fall within the temperature of the HTF. Besides, molten salts have been widely considered by researchers for medium to high temperature thermal storage [54]. In addition they possess high latent heat which allows for a more compact TES tank [52,58]. To relieve such issues as leakage, corrosion, as well as improve heat conductivity, the inorganic PCM was encapsulated in a high corrosion resistance and thermally stable material. The capsule material is made of stainless steel, with a thermal conductivity of $16.0 \mathrm{Wm}^{-1} \mathrm{~K}^{-1}$, density of $7920 \mathrm{kgm}^{-3}$ and a specific heat of $499 \mathrm{Jkg}^{-1} \mathrm{~K}^{-1}$ [50]. Also, an effective thermal conductivity is used in the model to improve thermal conductivity of the selected PCMs [59]. The advantages of encapsulation are [52,53,59]: decrease of the reactivity of the PCMs with the external environment,(2) enhancement of heat transfer due to the large surface to volume ratio of the capsules, (3) enhancement in cycling stability since phase separation is restricted to microscopic distances, and (4) no leakage during its liquid phase for some PCMs. Table 1 shows some of the most important properties of the selected PCMs.

Table 1 Selected PCM properties[12][60][54]

\begin{tabular}{|c|c|c|c|c|c|c|c|c|c|}
\hline \multirow[t]{2}{*}{ No } & \multirow[t]{2}{*}{ PCM } & \multirow[t]{2}{*}{$\boldsymbol{T}_{\boldsymbol{m}}\left({ }^{\circ} \mathrm{C}\right)$} & \multicolumn{2}{|c|}{$c_{P}\left(k J k g^{-1} K\right)$} & \multicolumn{2}{|c|}{$k\left(W m k^{-1}\right)$} & \multicolumn{3}{|c|}{$L_{m}\left(k_{J} k^{-} \rho\left(k g m^{-3}\right)\right.$} \\
\hline & & & $\mathrm{S}$ & 1 & $\mathrm{~S}$ & 1 & & $\mathrm{~S}$ & 1 \\
\hline 1 & $\mathrm{NaNO}_{3}$ & 306 & 1100 & & 0.5 & & 172 & 2100 & \\
\hline 2 & $\mathrm{NaNO}_{2}$ & $277-303$ & 1385 & 1514 & 0.56 & 0.48 & 199.6 & 2097 & 1873 \\
\hline 3 & $\begin{array}{l}\mathrm{NaNO}_{3} \\
-\mathrm{KNO}_{3}\end{array}$ & 220 & 950 & 1360 & 0.56 & & 100.7 & 1790 & \\
\hline
\end{tabular}

$\mathrm{s}$ in the table denote solid and 1 , liquid. 


\section{Mathematical model}

\subsection{Modelling the A-CAES}

The temperature $\left(\mathrm{T}_{\mathrm{TEST}, \mathrm{i}}\right)$ and mass flow of $\left(\dot{m}_{A C}\right)$ of the CA entering the TEST for mod1 is obtained as follows:

$$
\begin{aligned}
& \mathrm{T}_{\mathrm{TEST}, \mathrm{i}}=\mathrm{T}_{\mathrm{amb}}\left[1+\frac{\beta^{\frac{\gamma-1}{\gamma}}-1}{\eta_{\text {isen }}}\right] \\
& \dot{\mathrm{m}}_{\mathrm{a}, \mathrm{AC}}=\frac{\dot{\mathrm{W}}_{\mathrm{WT}} n_{\mathrm{isen}} \eta_{\mathrm{m}}}{2 \mathrm{C}_{\mathrm{p}, \mathrm{a}} \mathrm{T}_{\mathrm{amb}}\left(\beta^{\frac{\gamma-1}{\gamma}}-1\right)}
\end{aligned}
$$

Where $\dot{W}, T, \beta, \gamma, \eta, C_{p}$ signify power $(W)$, temperature $(K)$, stage pressure ratio, ratio of air specific heat, efficiency and constant pressure specific heat $\left(\mathrm{Jkg}^{-1} \mathrm{~K}^{-1}\right)$ respectively. Subscripts WT, i, m, isen, amb AC, and a signify wind turbine, in/inlet/input, mechanical, isentropic, ambient, air compressor and air respectively.

In mod2, supposing insignificant heat losses, in each compressor stage, heat is transferred from the hot air electric heater to the hot $\mathrm{CA}$, from the compressor at a rate according to the following equation:

$$
\mathrm{q}_{\text {heater }}=\dot{\mathrm{m}}_{\mathrm{a}, \mathrm{AC}} \times \mathrm{C}_{\mathrm{p}, \mathrm{a}}\left(\mathrm{T}_{\mathrm{a}, \mathrm{e}}-\mathrm{T}_{\mathrm{a}, \mathrm{i}}\right)=\psi \times \mathrm{\eta}_{\mathrm{m}} \times \mathrm{W}_{\mathrm{WT}} / 2
$$

The temperature and mass flow rate of the HTF entering the bed after passage in the heater is given as follows:

$$
\begin{gathered}
\mathrm{T}_{\mathrm{TEST}, \mathrm{i}}=\mathrm{T}_{\mathrm{amb}}\left[1+\frac{\beta^{\frac{\gamma-1}{\gamma}}-1}{\eta_{\text {isen }}}\right]+\psi \times \eta_{\mathrm{m}} \times \dot{\mathrm{W}}_{\mathrm{WT}} /\left(2 \dot{\mathrm{m}}_{\mathrm{a}, \mathrm{AC}} \times \mathrm{C}_{\mathrm{p}, \mathrm{a}}\right) \\
\dot{\mathrm{m}}_{\mathrm{a}, \mathrm{AC}}=\frac{\dot{\mathrm{W}}_{\mathrm{WT}} \times \eta_{\mathrm{isen}} \times \eta_{\mathrm{m}}[1-\psi]}{2 \mathrm{C}_{\mathrm{p}, \mathrm{a}} \times \mathrm{T}_{\mathrm{amb}}\left(\beta^{\frac{\gamma-1}{\gamma}}-1\right)}
\end{gathered}
$$

Where $\psi$ denotes the fraction of the wind turbine power used to power the electrical heater. Table 2 shows the summary of the operating characteristics of the two modes.

Table 2 Operating characteristics of the two modes

\begin{tabular}{lll}
\hline Characteristics & $\bmod 1$ & $\bmod 2$ \\
\hline Power of wind turbine $\left(\dot{\mathbf{W}}_{\mathbf{W T}}\right), \mathbf{M W}$ & 20 & 20 \\
Fraction of wind turbine power $(\boldsymbol{\psi})$ & 0 & 0.1 \\
CA inlet temperature to TEST $\left(\mathbf{T}_{\mathbf{T E S}, \mathbf{i}}\right),{ }^{\circ} \mathrm{C}$ & 327 & 360 \\
CA flow into TEST $\left(\dot{\mathbf{m}}_{\mathbf{a}, \mathbf{A C}}\right), \mathbf{k g s} \mathbf{k g}^{-\mathbf{1}}$ & 32.9 & 29.64 \\
CA mass flow out of bed $\left(\dot{\mathbf{m}}_{\mathbf{a}, \mathbf{A C}}\right), \mathbf{k g s}^{\mathbf{- 1}}$ & 32.9 & 29.64 \\
\hline
\end{tabular}


Ignoring any loss of heat in the connecting pipes, the numerically computed outlet mass flow rate and temperature of CA from the A-CAES during the charging phase equals the inlet temperature of the TEST at all times.

3.2. Modelling the TEST

3.2.1 Assumptions

To model the transient temperature distribution of the PCM and HTF within the TEST, the concentric dispersion model (CDM) is employed. The CDM treats a TEST as an isotropic porous medium made up of independent spherical particles, in which the fluid have dispersed plug flow and the intra-particle temperature profile is symmetrical.

The following assumptions were adopted[61]:

- The fluid flow is laminar and incompressible and the flow rate is constant with time

- Thermo-physical properties of HTF are temperature independent but evaluated at mean average temperature $\mathrm{T}_{\text {ave }}=0.5\left(\mathrm{~T}_{\mathrm{TEST}, \mathrm{i}}+\mathrm{T}_{\mathrm{amb}}\right)$

- The convection effects existing during the melting of the PCM are accounted for via the use of an effective conduction coefficient $\left(\mathrm{k}_{\mathrm{ef}}\right)$ in the energy equation.

- The PCMs in the TEST are immiscible and each is isotropic and homogenous;

- The thermo-physical properties of PCM's do not depend on temperature but differ for solid and liquid phases

- The PCM is originally in solid state

- Heat loss from the TEST reservoir is by conduction and convection only

- Thermal conduction in the PCM in the axial direction is ignored

- Effective thermal conductivity of PCM is the mean of thermal conductivity of the solid $\left(\mathrm{k}_{\mathrm{s}}\right)$ and liquid $\left(\mathrm{k}_{\mathrm{l}}\right)$ PCM.

- Density at the mushy state is the average densities of the PCM in the liquid and solid states.

- The heat loss from the TEST is by conduction and convection only

\subsubsection{Governing mathematical equations for HTF and PCM}

Based on the preceding assumptions, the energy equation for the HTF is as follows:

$$
\frac{\partial\left(\epsilon \mathrm{Ah}_{\mathrm{a}} \mathrm{d} x\right)}{\partial \mathrm{t}}+\dot{\mathrm{m}}_{\mathrm{a}} \frac{\partial\left(\mathrm{h}_{\mathrm{a}} \mathrm{d} x\right)}{\partial x}=\mathrm{Ah}_{\mathrm{v}} \mathrm{dx} \Delta \mathrm{T}_{\mathrm{c}, \mathrm{a}}+\mathrm{U}_{\mathrm{w}} \mathrm{C}_{\mathrm{w}} \mathrm{dx} \Delta \mathrm{T}_{\mathrm{amb}, \mathrm{a}}+\operatorname{Adx} . \nabla \cdot\left(\mathrm{k}_{\mathrm{a}, \mathrm{ef}} \nabla \mathrm{T}_{\mathrm{a}}\right)
$$

Where T and $\theta$ are the CA and PCM temperatures respectively. $\mathrm{C}_{\mathrm{w}}$ is the circumference $(\mathrm{m})$ of cylindrical bed, $\Delta \mathrm{T}_{\mathrm{c}, \mathrm{a}}=\left(\theta-\mathrm{T}_{\mathrm{a}}\right)$ and $\Delta \mathrm{T}_{\mathrm{a}, \mathrm{amb}}=\left(\mathrm{T}_{\mathrm{a}}-\mathrm{T}_{\mathrm{amb}}\right), \mathrm{A}$ is the superficial area of the bed $\left(\mathrm{m}^{2}\right), \mathrm{h}$ is enthalpy $\left(\mathrm{Jkg}^{-1}\right), \epsilon$ is porosity, $\mathrm{x}$ is axial coordinate $(\mathrm{m}), \mathrm{U}$ is overall heat transfer coefficient $\left(\mathrm{Wm}^{-2} \mathrm{~K}^{-1}\right), \mathrm{v}_{\mathrm{a}}$ is superficial velocity of CA entering TEST in $\mathrm{ms}^{-1}, \mathrm{~h}_{\mathrm{v}}$ is volumetric heat transfer coefficient $\left(\mathrm{Wm}^{-3} \mathrm{~K}^{-1}\right)$ and subscripts $\mathrm{c}$, a, ef and w denote PCM, air, effective, and wall, respectively.

The energy transfer in the PCM is modelled using the general equation for radially symmetric heat conduction in polar coordinates as follows [62]:

$$
\frac{1}{\alpha}\left(\frac{\partial \theta}{\partial \mathrm{t}}\right)=\frac{1}{\mathrm{r}^{\sigma}} \nabla \cdot\left(\mathrm{r}^{\sigma} \nabla \cdot \theta\right)=\left(\frac{\partial^{2} \theta}{\partial r^{2}}+\frac{\sigma}{r} \frac{\partial \theta}{\partial r}\right), \text { for } \mathrm{r} \neq 0
$$

Where $\sigma=0$ for a plane wall, $\sigma=1$ for a cylinder, and $\sigma=2$ for a sphere [62] and $\mathrm{k}$ is thermal conductivity $\left(\mathrm{Wm}^{-1} \mathrm{~K}^{-1}\right), \rho$ is density $\left(\mathrm{kgm}^{-3}\right)$ and $\alpha$ is thermal diffusivity in $\mathrm{m}^{2} \mathrm{~s}^{-1}$ which is expressed as $\alpha=k / \rho \mathrm{C}_{\mathrm{p}}$. Values of $\rho, \mathrm{C}_{\mathrm{p}}$ and $\mathrm{k}$ are dependent on the temperature of PCM. Heat 
transfer in the PCM storage vessel is dominated by natural convection in the liquid phase. This mechanism is accounted for in the model using an effective thermal conductivity in the solidliquid phase [12,27,63]. The effective thermal conductivity of the air $\left(\mathrm{k}_{\mathrm{a}, \mathrm{ef}}\right)$ is as follows [64]:

$$
\frac{\mathrm{k}_{\mathrm{a}, \mathrm{ef}}}{\mathrm{k}_{\mathrm{a}}}=\frac{\mathrm{k}_{\mathrm{se}}^{0}}{\mathrm{k}_{\mathrm{a}}}+0.5 \mathrm{P}_{\mathrm{r}} \operatorname{Re}_{\mathrm{c}}
$$

Where $\mathrm{k}$ is sthermal conductivity $\left(\mathrm{Wm}^{-1} \mathrm{~K}^{-1}\right), \mathrm{k}_{\mathrm{s}, \mathrm{e}}^{0}$ is the efective stagnation thermal conductivity estimated from $\mathrm{k}_{\mathrm{se}}^{0}=\mathrm{k}_{\mathrm{a}}\left[\frac{\mathrm{k}_{\mathrm{s}}}{\mathrm{k}_{\mathrm{a}}}\right]^{\mathrm{q}}$ and subscript s denote solid.

$$
\mathrm{q}=0.280-0.757 \log \epsilon-0.057 \log \left[\mathrm{k}_{\mathrm{s}} / \mathrm{k}_{\mathrm{a}}\right]
$$

The external convection heat transfer coefficient $\left(h_{c}\right)$ is obtained as follows [65]:

Where

$$
\mathrm{h}_{\mathrm{c}}=\frac{\mathrm{k}_{\mathrm{a}, \mathrm{ef}} \mathrm{Nu}_{\mathrm{c}}}{\mathrm{d}_{\mathrm{c}}}
$$

The volumetric heat transfer coefficient $\left(\mathrm{h}_{\mathrm{v}}\right)$ for the capsule is as follows:

$$
h_{\mathrm{v}}=\frac{3(1-\epsilon)}{\left(\mathrm{r}_{\mathrm{c}, \mathrm{i}}+\mathrm{x}_{\mathrm{c}}\right)} \mathrm{h}_{\mathrm{ef}}
$$

Where $r_{c, i}$ is capsule internal radius $(m), x_{c}$ is PCM capsule thickness $(m)$ and $h_{e f}$ is the effective heat transfer coefficient $\left(\mathrm{Wm}^{-2} \mathrm{~K}^{-1}\right)$ which is given as:

$$
\mathrm{h}_{\mathrm{ef}}=\frac{1}{\mathrm{R}_{\text {conv }}+\mathrm{R}_{\text {cond }}} \frac{1}{\left(1+0.2 \mathrm{~B}_{\mathrm{i}}\right)}
$$

$\mathrm{R}_{\text {conv }}$ and $R_{\text {cond }}$ denote thermal resistance due to convection and conduction on the external surface of the PCM shell and through the shell thickness respectively as follows [66]:

$$
\begin{gathered}
\mathrm{R}_{\text {cond }}=\frac{\left(\left(\mathrm{r}_{\mathrm{c}, \mathrm{i}}+\mathrm{x}_{\mathrm{c}}\right)-\mathrm{r}_{\mathrm{p}, \mathrm{i}}\right)}{\mathrm{k}_{\mathrm{c}}}\left\langle\frac{\mathrm{r}_{\mathrm{c}, \mathrm{i}}}{\left(\mathrm{r}_{\mathrm{c}, \mathrm{i}}+\mathrm{x}_{\mathrm{c}}\right)}\right\rangle \\
\mathrm{R}_{\text {conv }}=\left[\frac{\mathrm{r}_{\mathrm{c}, \mathrm{i}}}{\left(\mathrm{r}_{\mathrm{c}, \mathrm{i}}+\mathrm{x}_{\mathrm{c}}\right)}\right]^{2}\left\langle\frac{1}{\mathrm{~h}_{\mathrm{c}}}\right\rangle
\end{gathered}
$$

The Reynolds number ( $\mathrm{Re})$ is calculated as follows:

$$
\operatorname{Re}=\rho v_{\mathrm{a}} \mathrm{d}_{\mathrm{c}} / \mu
$$

Where $d_{c}$ is capsule diameter and $\mu$ is HTF viscosity. The porosity of the packed bed is calculated as follows [67]:

\subsubsection{Boundary and initial conditions}

The following initial and boundary conditions were adopted for the HTF and PCM. HTF:

$$
\mathrm{T}_{\mathrm{a}}(\mathrm{x}, 0)=\mathrm{T}_{\text {initial }} ; \mathrm{T}_{\mathrm{a}}(0, \mathrm{t})=\mathrm{T}_{\mathrm{TEST}, \mathrm{i}}(\mathrm{t}) \text { and } \frac{\partial \mathrm{T}(\mathrm{L}, \mathrm{t})}{\partial \mathrm{x}}=0
$$

PCM and capsule wall

$$
\begin{gathered}
\theta(\mathrm{r}, \mathrm{t}=0)=\theta_{\text {initial }} ; \theta_{w}(\mathrm{r}, \mathrm{t}=0)=\theta_{\text {initial }} ; \quad \frac{\partial \mathrm{T}(\mathrm{R}, \mathrm{t})}{\partial \mathrm{r}}=0 \\
-\mathrm{k}_{\mathrm{w}} \frac{\partial \theta(0, \mathrm{t})}{\partial \mathrm{r}}=\mathrm{h}_{\mathrm{c}}\left(\mathrm{T}_{\mathrm{a}}-\theta_{\mathrm{w}}\right)
\end{gathered}
$$




\subsection{Solution Method}

The mathematical models developed in the preceding section is solved using finite difference method. An implicit backward difference in space and forward difference in time finite difference technique is used

\subsubsection{Implicit difference formulation for the HTF and PCM}

Substituting finite difference approximations for the derivatives in the heat conduction equation (Eq. 7), and rearranging the resulting expression, the implicit finite difference equation for each grid point (i) at any time (t) for the HTF energy equation (Eq. 7) can be written as follows:

$$
\mathrm{T}_{\mathrm{i}-1}^{\mathrm{t}+1}(-\mathrm{A}-\mathrm{B})+\mathrm{T}_{\mathrm{i}}^{\mathrm{t}+1}(1+2 \mathrm{~B}+\mathrm{A}+\mathrm{C}+\mathrm{D})+\mathrm{T}_{\mathrm{i}+1}^{\mathrm{t}+1}(-\mathrm{B})=\mathrm{T}_{\mathrm{i}}^{\mathrm{t}}+\theta^{\mathrm{t}}(\mathrm{C})+\mathrm{T}_{\infty}(\mathrm{D})
$$

Where

$$
\mathrm{A}=\frac{\dot{\mathrm{m}} \Delta \mathrm{t}}{\epsilon \rho \mathrm{Adx}}, \mathrm{B}=\frac{\mathrm{k} \Delta \mathrm{t}}{\epsilon \rho \mathrm{C}_{\mathrm{p}} \Delta \mathrm{x}^{2}}, \mathrm{C}=\frac{\mathrm{h}_{\mathrm{v}} \Delta \mathrm{t}}{\epsilon \rho \mathrm{C}_{\mathrm{p}}} \text { and } \mathrm{D}=\frac{\mathrm{U}_{\mathrm{w}} \mathrm{C}_{\mathrm{w}} \Delta \mathrm{t}}{\epsilon \rho \mathrm{C}_{\mathrm{p}} \mathrm{A}}
$$

At the end node, $\mathrm{x}=\mathrm{L}, \mathrm{i}=\mathrm{i}_{\max }$ and $\partial \mathrm{y} / \partial \mathrm{x}=0, \rightarrow \mathrm{T}_{\mathrm{i}-1}=\mathrm{T}_{\mathrm{i}+1}$

Substituting $i=i_{\max }$ in Eq. 22 and replacing $\mathrm{T}_{\mathrm{i}-1}$ with $\mathrm{T}_{\mathrm{i}+1}$, we arrive at the expression for the nodal temperature at the end of the TEST as follows:

$$
\mathrm{T}_{\mathrm{i}_{\text {max }}-1}^{\mathrm{t}+1}(-\mathrm{A}-2 \mathrm{~B})+\mathrm{T}_{\mathrm{i}_{\text {max }}}^{\mathrm{t}+1}(1+2 \mathrm{~B}+\mathrm{A}+\mathrm{C}+\mathrm{D})=\mathrm{T}_{\mathrm{i}}^{\mathrm{t}}+\theta^{\mathrm{t}}(\mathrm{C})+\mathrm{T}_{\infty}(\mathrm{D})
$$

At any given time $(\Delta \mathrm{t})$, Equations (22 and 24$)$ can be written for each layer-giving rise to a system of $\mathrm{i} \times \mathrm{t}$ simultaneous equations.

The PCM is considered as spherical balls with series of nodes which span from the surface to the centre as in Figure 2.

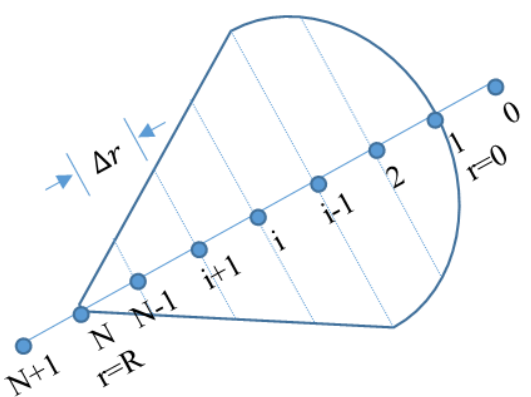

Figure 2: Grid points in the PCM

Visualising the spheres as consisting of $\mathrm{n}$ spherical shells of equivalent thickness $\Delta \mathrm{r}$. Sweeping from the surface to the centre, the temperature at the interphase of these shells will be designated as $\theta_{\mathrm{i}}\langle\mathrm{i}=1$, $\mathrm{N}\rangle$ with $\theta_{1}$ at $\mathrm{r}=\mathrm{O}$ and $\theta_{\mathrm{N}}$ at $\mathrm{r}=\mathrm{R}$

Thus;

$$
\begin{gathered}
\Delta r=\frac{R}{N} \\
R_{i}=(i-1) \Delta r, \quad i=1, \ldots \ldots . N+1 \\
\Delta r=R-(i-1) \Delta r, \quad i=1, \ldots \ldots . N+1
\end{gathered}
$$

By substituting the finite difference approximations for the derivatives according to the governing heat conduction equation (Eq. 8), and rearranging the resulting expression, the following equation is obtained for any universal internal grid point $\mathrm{i}$ : 
Where

$$
\theta_{\mathrm{i}-1}^{\mathrm{t}+1} E\langle-\mathrm{E}(1+F)\rangle+\theta_{\mathrm{i}}^{\mathrm{t}+1}\langle 1+2 \mathrm{E}\rangle+\theta_{\mathrm{i}+1}^{\mathrm{t}+1}\langle\mathrm{E}(F-1)\rangle=\theta_{\mathrm{i}}^{\mathrm{t}}
$$

$$
\mathrm{E}=\frac{\mathrm{k} \Delta \mathrm{t}}{\rho \mathrm{C}_{\mathrm{p}} \Delta \mathrm{r}^{2}}, \mathrm{~F}=\frac{\sigma \Delta \mathrm{r}}{2 \mathrm{r}}
$$

Equation (28) is descriptive of any $\mathrm{i}^{\text {th }}$ node except the surface $(\mathrm{r}=0)$ and centre $(\mathrm{r}=\mathrm{R})$ nodes. For the surface, the finite difference discretisation of the convective boundary condition is implemented to arrive at the following equation:

$$
\theta_{1}^{\mathrm{t}+1}\left(1+\mathrm{B}_{\mathrm{i}}\right)-\theta_{2}^{\mathrm{t}+1}=\mathrm{B}_{\mathrm{i}}\left(\mathrm{T}_{\mathrm{a}, \mathrm{i}}\right)
$$

At the centre, that is at $r=R$ and $i=N$, the term $\left(\theta_{i+1}^{t+1}\right)$ in the discretised equation (28) becomes a fictitious value since it falls outside the computational domain. However, since the PCM have symmetry at the origin; the following form of the heat equation is valid at the centre $[67,68]$ :

$$
\frac{\partial \theta}{\partial \mathrm{t}}=\langle\sigma+1\rangle \alpha \frac{\partial^{2} \theta}{\partial \mathrm{r}^{2}}
$$

The above equation is expressed in terms of its finite difference (FD) equivalent and rearranged to arrive at the following equation for the centre nodes:

$$
\theta_{\mathrm{imax}-1}^{\mathrm{t}+1}[-2 \mathrm{E}(1+\sigma)]+\theta_{\mathrm{imax}}^{\mathrm{t}+1}[1+2 \mathrm{E}(1+\sigma)]=\theta_{\mathrm{imax}}^{\mathrm{t}}
$$

Where $B_{i}=h \Delta r / k$

The resulting discretised finite difference system of equations for the HTF and PCM take the matrix form $[\mathrm{A}][\theta]=[\mathrm{b}]$.as follows [69]:

$$
\theta_{i-1}^{t+1} X_{i}+\theta_{i}^{t+1} Y_{i}+\theta_{i+1}^{t+1} Z_{i}=R H S_{i}^{t}
$$

A matrix inversion method was applied by means of a Matlab written computer code to obtain the complete profile of the transient nodal temperatures of the HTF and PCM.

\subsubsection{Capsule state judgment system (CSJS)}

The mechanism of transfer of heat during a phase change is a very complicated issue because the solid/liquid interface moves subject to the speed at which the latent heat is absorbed or lost at the boundary $[57,61]$. To integrate the melting/solidification effect in the solution, a capsule state judgment system (CSJS) is built into the Matlab routine, which analyses the information in every node according to its present state to determine the state of the PCM in each node. The algorithm makes use of the equivalent temperature-dependent thermo-physical property of the PCM that meets the characteristics of the phase change process inside the PCM [61]. The effective heat capacity method is employed to calculate specific heat because of its simplicity to use as it does not necessitate alteration of the dispersion concentric energy equations.

Table 3 summarises the computational judgment of the CSJS whereas the flow chart of the whole computational procedure adopted in Matlab is given in Figure 3. 
Table 3 Computational decision of the CSJS

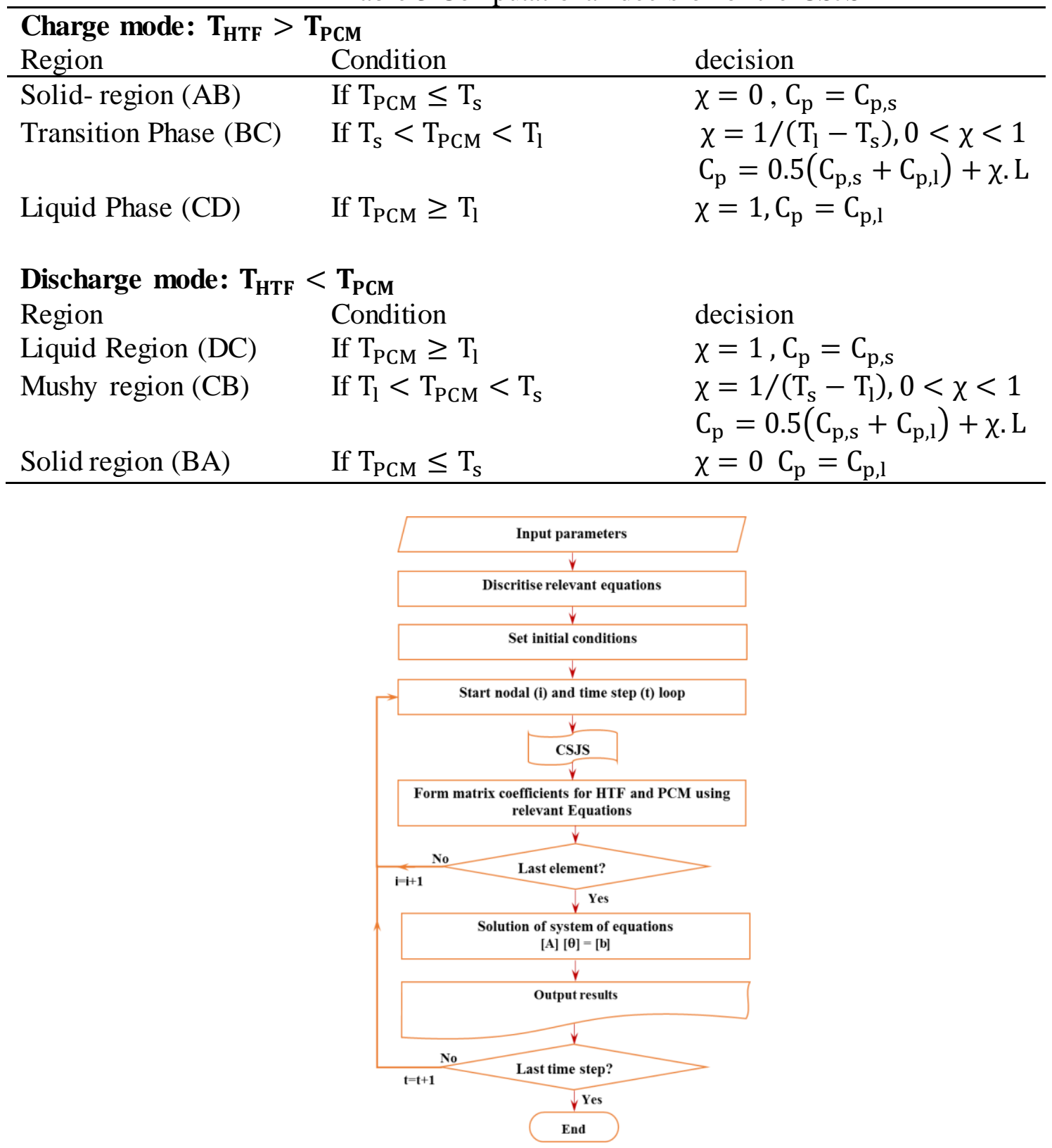

Figure 3: Flow chart of solution method

\subsection{Estimation of model parameters}

The specific heat capacity at constant pressure $\left(\mathrm{C}_{\mathrm{P}, \mathrm{a}}\right)$, thermal conductivity $\left(\mathrm{k}_{\mathrm{a}}\right)$, viscosity $\left(\mu_{\mathrm{a}}\right)$ and density $\left(\rho_{\mathrm{a}}\right)$ for air respectively were estimated at the average temperature $(\mathrm{T})$ using the following equations $[61,70,71]$ : 


$$
\begin{gathered}
\mathrm{C}_{\mathrm{P}, \mathrm{a}}=0.9992 \times 10^{3} \mathrm{~T}^{0}+1.4319 \times 10^{-1} \mathrm{~T}^{1}+1.1010 \times 10^{-4} \mathrm{~T}^{2}-6.7851 \\
\times 10^{-8} \mathrm{~T}^{3} \quad\left(\mathrm{Jkg}^{-1} \mathrm{~K}^{-1}\right) \\
\mathrm{k}_{\mathrm{a}}=0.0244+0.7673 \times 10^{-4} \mathrm{~T} \quad\left(\mathrm{Wm}^{-1} \mathrm{~K}^{-1}\right) \\
\mu_{\mathrm{a}}=1.718 \times 10^{-5}+4.620 \times 10^{-8} \mathrm{~T} \quad\left(\mathrm{kgm}^{-1} \mathrm{~s}^{-1}\right) \\
\rho_{\mathrm{a}}=\frac{353.44}{(\mathrm{~T}+273.15)}\left(\mathrm{kgm}^{-3}\right)
\end{gathered}
$$

Where $\mathrm{T}$ is in ${ }^{\circ} \mathrm{C}$

The pressure drop along the TEST is calculated as follows [72]:

$$
\Delta \mathrm{p}_{\text {TEST }}=\frac{\mathrm{LG}^{2}}{\rho_{\mathrm{a}} \mathrm{d}_{\mathrm{c}}}\left(1.75 \frac{1-\epsilon}{\epsilon^{3}}+150 \frac{(1-\epsilon)^{2}}{\epsilon^{3} \times \mathrm{Re}_{\mathrm{m}}}\right)
$$

Where $\mathrm{G}$ is mass flux given as $\dot{\mathrm{m}}_{\mathrm{a}} / \mathrm{A}_{\text {TEST }}\left(\mathrm{kgm}^{-2} \mathrm{~s}^{-1}\right), \mathrm{Re}_{\mathrm{m}}$ is the modified Reynolds number defined as $\mathrm{Gd}_{c} / \mu_{\mathrm{a}}$ where $\mu_{\mathrm{a}}$ is the fluid viscosity and $d_{c}$ is the diameter of the PCM.

\section{Parametric analysis}

\begin{tabular}{|c|c|c|}
\hline Ar1 & Ar2 & Ar3 \\
\hline 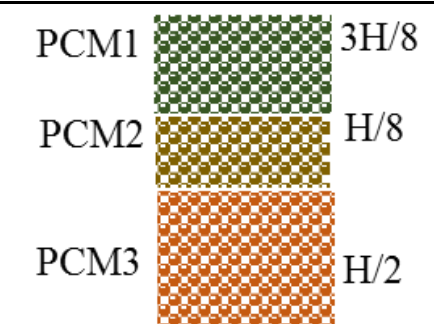 & 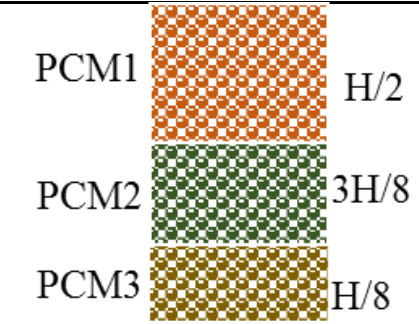 & 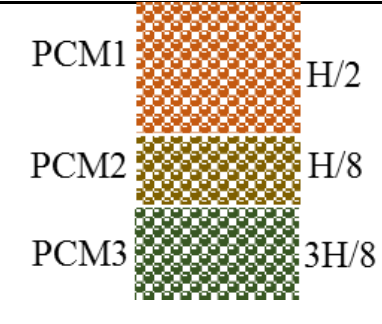 \\
\hline
\end{tabular}

A parametric study was implemented to analyse the impact of the height occupied by each of the three different PCMs on the performance of the two modes studied. Three variants of PCM packing height arrangement were considered here.

Table 1 shows the summary of the PCM packing options considered in the parametric analysis.

Table 1 PCM arrangement (Ar) options for parametric analysis

\section{Performance metrics}

The TES performance of the system is assessed using commonly deployed metrics such as charged or discharged energy, energy efficiency and exergy efficiency.

The rate of energy input $\left(\mathrm{q}_{\mathrm{i}}(\mathrm{t})\right)$ and stored energy $\mathrm{q}_{\mathrm{st}}(\mathrm{t})$ is calculated as follows[51,73]:

$$
\begin{gathered}
\mathrm{q}_{\mathrm{i}}(\mathrm{t})=\dot{\mathrm{m}}_{\mathrm{a}, \mathrm{i}} \mathrm{C}_{\mathrm{p}, \mathrm{a}}\left(\mathrm{T}_{\mathrm{a}, \mathrm{i}}(\mathrm{t})-\mathrm{T}_{\mathrm{a}, \mathrm{e}}(\mathrm{t})\right) \\
\mathrm{q}_{\mathrm{st}}(\mathrm{t})=\mathrm{q}_{\mathrm{i}}(\mathrm{t})-\mathrm{q}_{\text {loss }}(\mathrm{t})
\end{gathered}
$$

The charging and discharging energy efficiency $\left(\right.$ EnEff $\left._{\mathrm{ch}} \& \mathrm{EnEff}_{\mathrm{dch}}\right)$ is estimated as follows:

$$
\operatorname{EnEff}_{c h}(t)=\frac{q_{s t}(t)}{q_{i}(t)+q_{\text {pump,ch }}}
$$




$$
\operatorname{EnEff}_{d c h}(t)=\frac{q_{e}(t)}{q_{s t}(t)+q_{\text {pump,dch }}}
$$

Where the pumping energy is given as follows:

$$
\mathrm{q}_{\text {pump }}=\sum_{t=0}^{t}\left(\Delta p_{T E S T} \times \dot{m} \times \Delta t\right) / \rho
$$

The energy recovered $\left(\mathrm{q}_{\mathrm{e}}\right)$ during the dischard cycle is given as follows:

$$
\mathrm{q}_{\mathrm{e}}(\mathrm{t})=\mathrm{m}_{\mathrm{a}, e} \mathrm{C}_{\mathrm{p}, \mathrm{a}}\left(\mathrm{T}_{\mathrm{a}, \mathrm{e}}(\mathrm{t})-\mathrm{T}_{\mathrm{a}, \mathrm{i}}(\mathrm{t})\right)
$$

The round trip efficiency of the system (RTE) is defined as the fraction of the recovered energy in the discharging cycle to the input energy in the charging cycle. It can also be stated as the product of energy efficiency of the charging and discharging cycles.

$$
\operatorname{RTE}(\mathrm{t})=\frac{\mathrm{q}_{\mathrm{e}}(\mathrm{t})}{\mathrm{q}_{\mathrm{i}}(\mathrm{t})}=\operatorname{EnEff}_{\mathrm{ch}} \times \operatorname{EnEff}_{\mathrm{dch}}
$$

The charging exergy efficiency (ExEff) is defined as the proportion of the stored exergy $\left(\overrightarrow{E x}_{\mathrm{s}}\right)$ to the exergy input $\left(\mathrm{Ex}_{\mathrm{i}}\right)$ as follows:

Where:

$$
\operatorname{ExEff}(t)=\frac{\dot{\operatorname{Ex}_{s}}(t)}{\dot{\operatorname{Ex}_{i}(t)}}
$$

$$
\dot{E x}_{\mathrm{i}}(\mathrm{t})=\dot{\mathrm{m}}_{\mathrm{a}, i} \mathrm{C}_{\mathrm{p}, \mathrm{a}}\left(\left(\mathrm{T}_{\mathrm{a}, \mathrm{i}}(\mathrm{t})-\mathrm{T}_{\mathrm{a}, \mathrm{e}}(\mathrm{t})\right)-\mathrm{T}_{\mathrm{amb}}\left(\ln \frac{\mathrm{T}_{\mathrm{a}, \mathrm{i}}(\mathrm{t})}{\mathrm{T}_{\mathrm{a}, \mathrm{e}}(\mathrm{t})}\right)\right)
$$

The stored exergy in the TEST is calculated as follows [74]:

$$
\dot{E x}_{\mathrm{s}}(\mathrm{t})=\dot{E x}_{\mathrm{i}}(\mathrm{t})-\mathrm{q}_{\text {loss }}(\mathrm{t})\left[1-\frac{\mathrm{T}_{\mathrm{amb}}}{\mathrm{T}_{\mathrm{ave}}(\mathrm{t})}\right]
$$

The exergy efficiency of the discharging cycle is the ratio of the exergy output $\left(\dot{E x}_{\mathrm{e}}\right)$ to the stored exergy $\left(\dot{\mathrm{Ex}}_{\mathrm{s}}\right)$ as follows:

Where:

$$
\operatorname{ExEff}(\mathrm{t})=\frac{\dot{\operatorname{Ex}_{\mathrm{e}}}(\mathrm{t})}{\dot{\mathrm{Ex}}_{\mathrm{s}}(\mathrm{t})}
$$

$$
\dot{E x}_{\mathrm{e}}(\mathrm{t})=\dot{\mathrm{m}}_{\mathrm{a}, \mathrm{e}} \mathrm{C}_{\mathrm{p}, \mathrm{a}}\left(\left(\mathrm{T}_{\mathrm{a}, \mathrm{e}}(\mathrm{t})-\mathrm{T}_{\mathrm{a}, \mathrm{i}}(\mathrm{t})\right)-\mathrm{T}_{\mathrm{amb}}\left(\ln \frac{\mathrm{T}_{\mathrm{a}, \mathrm{e}}(\mathrm{t})}{\mathrm{T}_{\mathrm{a}, \mathrm{i}}(\mathrm{t})}\right)\right)
$$

Finally the overall exergy efficiency of TEST is estimated as the product of the charging and discharging exergy efficiency.

6. Results and discussion

\subsection{Grid independent study}

Research has shown that the accuracy of numerical simulation results might depend on both the time step and grid spacing used in a model. [75]. To guarantee the results from the developed model is independent of the time step and grid spacing, the grid meshing and time step were continually varied until a negligible change in the variations in the predicted temperature histories of the HTF was obtained. It can be observed in Figure 4 that as the nodes 
increased from 120 (axial) $\times 40$ (radial) to 480 (axial) $\times 40$ (radial) there was a significant change in the temperature histories of the HTF

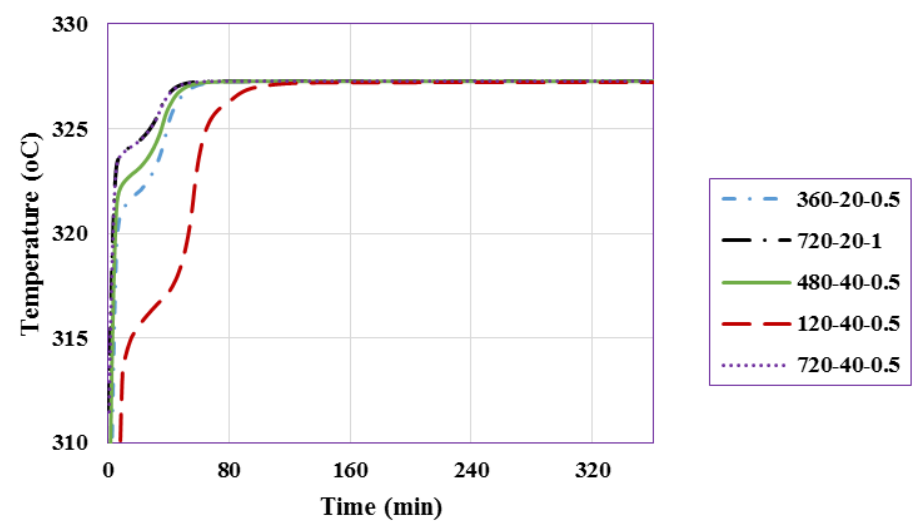

Figure 4: Temperature histories of the HTF at different computational grids

However, between nodes 480 (axial) $\times 40$ (radial) to 720 (axial) $\times 40$ (radial), an insignificant change in the temperature histories of the HTF is observed.

Moreover, as can be seen in Table 2, as the number of nodes of the TEST and the PCM in the axial and radial direction $\left(\mathrm{N}_{\mathrm{X}} \times \mathrm{R}_{\mathrm{X}}\right)$ respectively increased from 120 (axial) x 20 (radial) elements in the PCM with a time step of $1.0 \mathrm{~min}$ and $480 \times 20$ elements with a time step of $1 \mathrm{~min}$, the percentage difference in the stored energy is about $0.55 \%$ [61].

Table 2 Stored energy at different computational grid.

\begin{tabular}{ccc}
\hline $\begin{array}{c}\text { Grid } \\
(\boldsymbol{N} \boldsymbol{x} \times \boldsymbol{R} \boldsymbol{x})\end{array}$ & $\boldsymbol{\Delta t}(\boldsymbol{m i n})$ & $\begin{array}{c}\text { Average stored } \\
\text { heat }(\mathrm{MW})\end{array}$ \\
\hline $\mathbf{1 2 0} \times \mathbf{4 0}$ & 0.5 & 2.379 \\
$\mathbf{3 6 0} \times \mathbf{2 0}$ & 1 & 2.385 \\
$\mathbf{4 8 0} \times \mathbf{2 0}$ & 1 & 2.386 \\
$\mathbf{4 8 0} \times \mathbf{4 0}$ & 0.5 & 2.392 \\
$\mathbf{7 2 0} \times \mathbf{4 0}$ & 0.5 & 2.395 \\
$\mathbf{7 2 0} \times \mathbf{2 0}$ & 1 & 2.395 \\
$\mathbf{1 2 0 0} \times \mathbf{4 0}$ & 1 & 2.396 \\
$\mathbf{1 2 0 0} \times \mathbf{2 0}$ & 1 & 2.395 \\
\hline
\end{tabular}

As the meshing is enlarged more to $1200 \times 40$ at $\Delta \mathrm{t}=1 \mathrm{~min}$, the stored energy obtained from the two grids are near and the percentage differences of $0.17 \%$ between them is insignificant. Since the implicit time-discretization scheme used in the model discretization.is unconditionally stable for all values of time step [75] and factoring in both the precision and computation time, simulations reported in this study were all conducted using a time step of 1 min and a 720 x 40 computational domain

\subsection{Validation}

The present numerical code is validated by comparing its prediction with the experimental result of Benmansour et al. [67] for a stainless steel cylindrical TEST. The bed is 
filled with PCM packing of $31.8 \mathrm{~mm}$ diameter and the air is the HTF. The dimensions of the TEST are $60 \mathrm{~mm}$ height and $20 \mathrm{~mm}$ diameter with a wall thickness of $1 \mathrm{~mm}$. Its mean void fraction and bed-to-particle diameter ratio are 0.4056 and 6 respectively. Our simulation used the same conditions as in the experiment. The thermo-physical properties of the PCM are shown in

Table 3. The charging temperature history of PCM obtained numerically with the model is compared with the experimental results as in Figure 5. As can be seen from the figure, both experimental [67] and model predicted temperatures follow the same trend.

Table 3 Thermo physical proprieties of the paraffin wax. [67]

\begin{tabular}{ll}
\hline Property & Value \\
\hline Melting temperature & $60{ }^{\circ} \mathrm{C}$ \\
Latent heat of fusion & $189 \mathrm{~kJ} \mathrm{~kg}^{-1}$ \\
Thermal conductivity & $0.2406 \mathrm{Wm}^{-1} \mathrm{~K}^{-1}$ \\
Specific heat of Solid phase & $8.4 \mathrm{kJkg}^{-1} \mathrm{~K}^{-1}$ \\
Specific heat of Liquid phase & $2.1 \mathrm{Jkg}^{-1} \mathrm{~K}^{-1}$ \\
Solid phase density & $920 \mathrm{kgm}^{-3}$ \\
Liquid phase density & $795 \mathrm{kgm}^{-3}$ \\
\hline
\end{tabular}

Moreover, it can be observed that the values of temperature predicted by the model are fairly close to that of the experiment That is to say that the numerical prediction by the model is reasonable to enable its use for the comparison of the two modes. The deviation in the model predicted values to that of the experiment could be attributed to the various assumptions, approximations and fluid property correlations used including material properties of the PCM. The properties of the PCM at the mushy region was taken as the mean of the solid and liquid state properties. If the temperature-dependent material properties are known, the numerical results will be more accurate.

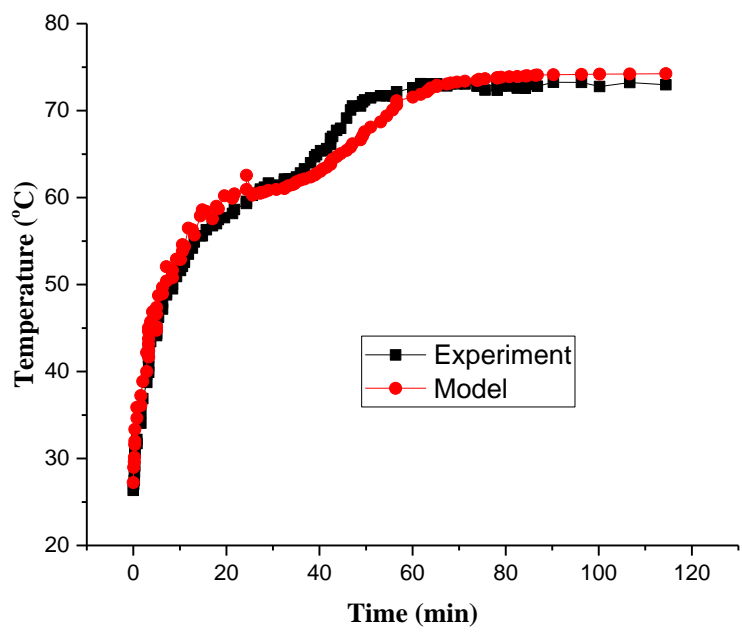

Figure 5: Experimental vs. Model predicted temperature histories of the PCM 


\subsection{Temperature histories of the PCM}

Figure $6(\mathrm{a}-\mathrm{c})$ displays the temperature features of the PCM at four distinct axial positions $(\mathrm{x}=$ $\mathrm{L}_{\mathrm{s}} / 4, \mathrm{~L}_{\mathrm{s}} / 2$, and $\mathrm{L}_{\mathrm{s}}$ ) in the three segments (top, middle and bottom) of the TEST for the two modes. It can be visualised that the temperature features of the PCM along the axial direction display similar trends in the three segments of the TEST in the tow modes. The time for melting of the PCMs in the three segments increased from the top segment to the last segment. This is because, throughout the charging cycle, the temperature of the charging HTF reduces along the tank height as the charging progressed and therefore the change in temperature between HTF and PCM reduces along the length of the TEST in the two modes, which leads to a slower charging rate for the PCMs in the lower segments of each section of the TEST. Observe from Figure 6(a), that for the two modes, a high heat transfer rate between the HTF and the PCM characterises the first stage of charging resulting to a sharp rise in the temperature of the HTF and PCM at a very fast rate in all the three segments of the TEST till the melting temperature of the PCM is reached. Using the case for $x=1$, it can be seen that $\bmod 2$ reached a higher temperature than mod 1 and the rate of increment of the temperatures in $\bmod 2$ is more compared to mod1. This is because the HTF in mod 2 is at a higher temperature since it was heated further
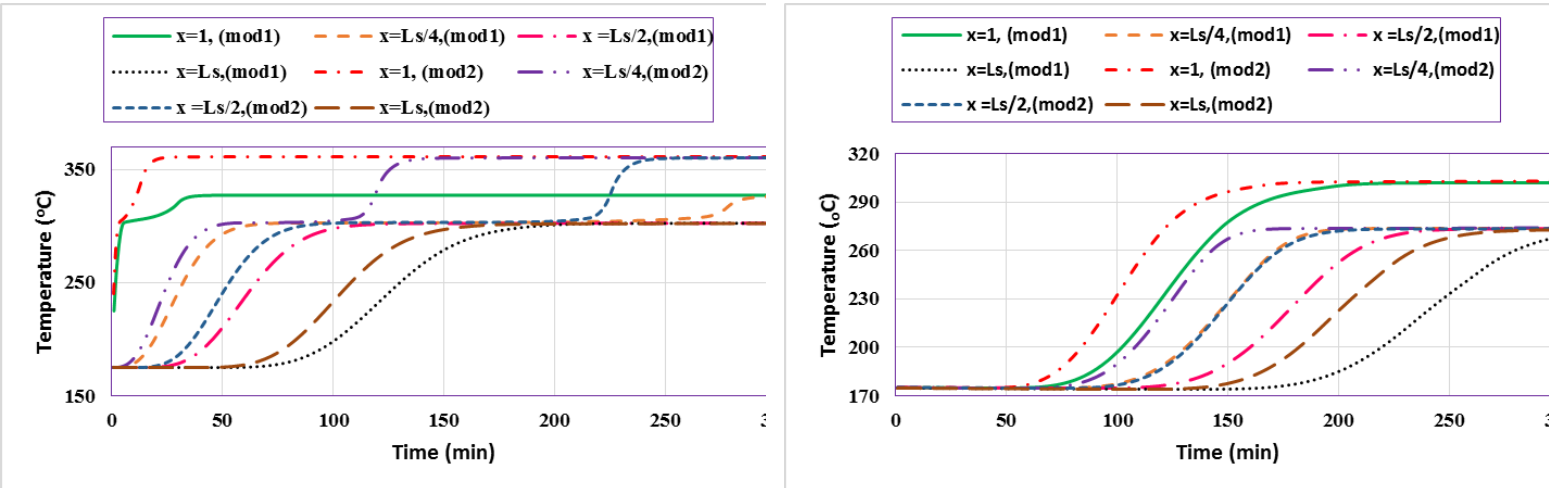

(a)

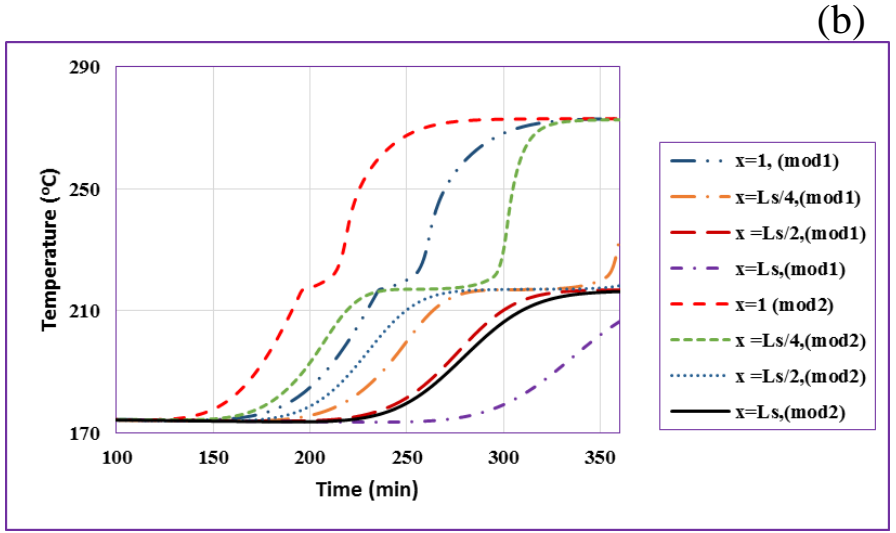

(c)

with an electric filament, thus enabling a higher rate of heat transfer between the HTF and the PCM in mod2. Although mod1 has a higher mass flow rate and the mass flow rate also impacts heat transfer rate positively, however, the rate of rise in heat transfer induced by the high temperature in mod 2 is more dominant than that brought about by the high mass flow rate of HTF in mod1. Accordingly, the temperature has a more overriding effect than the mass flow rate.

Figure 6: PCM outlet temperature at four locations of the TEST (a) top section , (b) middle section, (c) bottom section 
Figure 6(b) displays the temperature map of the mid-section of the TEST for both modes. It is significant to note that the PCMs filling this segment of the TEST took a longer time to liquefy when related to the top segment. This is because, as the charging time elapses, the change in temperature between the PCM and HTF reduces along the length of the TEST. Thus, the heat absorbed by the PCMs in this segment of the TEST is no more sufficient to bring about instantaneous melting of the PCMs. Rather the capsules absorb heat increasingly till the least threshold of temperature called the melting point of the PCMs is achieved and the PCMs liquefy. Although in this segment, the PCM in the two modes, achieved virtually the same uppermost temperature of about $290^{\circ} \mathrm{C}$, it can be seen that the rate of rising of the PCM temperature in mod2 remains higher in this segment than for mod1. In other words, mod2 melted faster, having taken about 150 minutes to melt whereas mod 1 melted in about 200 minutes. The above trend can further be explained by referring to temperature plot of the HTF along the length of the TEST as illustrated in Figure 7. As can be observed, in the first segment of the TEST $(H \approx 0-4 m)$, the temperature of the HTF in mod 2 is more compared to mod 1 . Therefore, due to the greater temperature of the inflowing HTF in mod2, there is a greater rate of heat transfer and hence the rising rate of the temperature of the PCM in the middle segment of the TEST is more in mod 2 than in mod1. The same trend is observed for the temperature profile of the HTF.

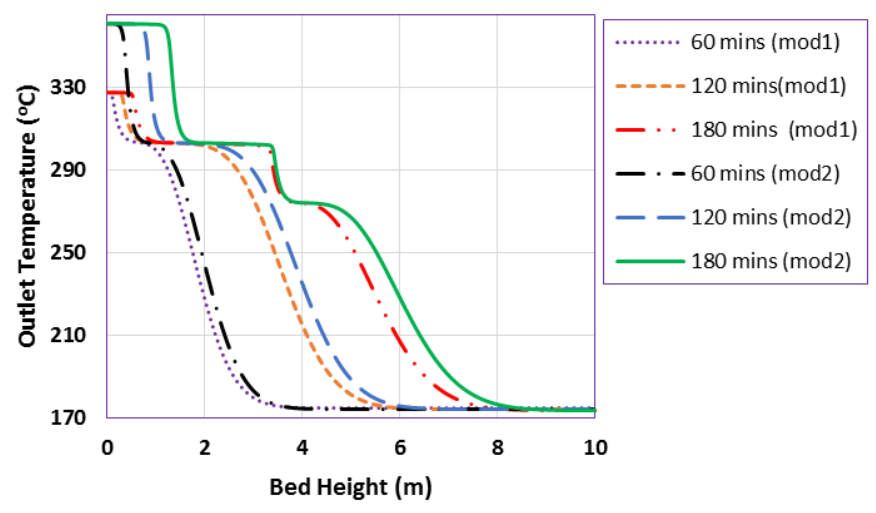

Figure 7: Temperature distribution of the HTF along the TEST during charging

In the bottom segment of the TEST for the charging operation (see Figure 6(c)), the same general trend noticed in the top and middle segments of the TEST is similarly witnessed here. The temperature profile at different heights in this segment showed the lowest phase change when compared to similar heights in the top and mid segments of the TEST because the exchange of heat between the HTF and the PCM is much slower in the bottom segment, owing to the lower HTF temperature than the middle and top sections of the TES as in Figure 7. In this segment, mod 2 melted at a smaller time of about 198 minutes and likewise took a shorter time to reach the highest temperature of $270{ }^{\circ} \mathrm{C}$. In contrast, mod1 took a long time of about 230 minutes to melt. Using the melting time observed in the mid-section of the TEST as a reference, it is estimated that $\bmod 2$ took about $32 \%$ more time to melt in the bottom segment of the TEST and for mod1 about $15 \%$ more time is taken to melt. Generally, the PCMs situated close to the exit of the bottom segments of the TEST remains solid, even for large operating times. This is because the energy carried by the HTF at these positions is not adequate to cause complete melting of the PCM. 


\subsection{Stored and accumulated energy}

Figure 8 displays the plot of the stored $\left(Q_{s}\right)$ and accumulated energy $\left(Q_{a c}\right)$ against time for the two modes. It can be observed that at first, the stored energy for the two modes is constant till after approximately 275 minutes in mod 2 and 225 minutes in mod 1 at which when the energy stored commenced declining moderately sharply as the charging progressed. This is because, as previously noted from the outlet temperature profile of PCM (Figure 6(a)) for the two modes, the initial sensible heat phase is very short whereas the latent heat phase is very lengthy and a substantial quantity of energy storage happens in the change of phase stage. Consequently, the high change in temperature between the HTF and the PCM melting temperatures results to high and constant values of charging rate thus emphasising the advantage of a LH TES system to provide constant heat rates $[20,61]$. After the phase change period, there is a slow but steady rise in the exit air temperature owing to the sensible heating of the melted PCM. This is because, once the PCM sensible heating commences, the PCM approaches its wholly charged state, making the transferred heat to the PCM by HTF to decrease progressively as the PCM approaches the end of the charging time. This results in a reduction in the change in temperature between the PCM and the HTF in the TEST as the charging operation proceeded leading to a lessening in energy transferred to the PCMs. Therefore the stored energy decreases over time. Furthermore, as the charging advanced, the cumulative heat stored by the PCM rises leading to growth in the temperature of the TEST tank and its contents. Consequently, this gives rise to enlarged heat loss from the storage tank as can be seen from Figure 9.

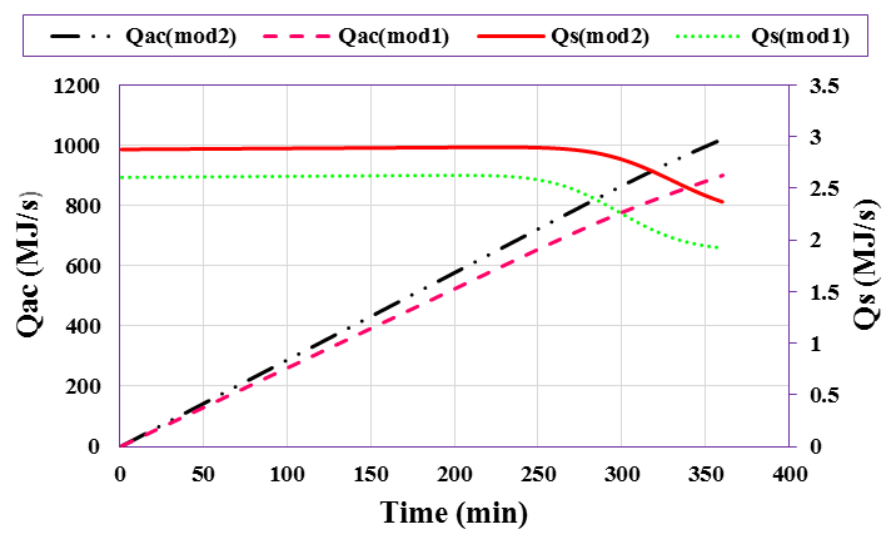

Figure 8: Stored and accumulated energy VS time

This increased heat loss also played a part in the perceived reduction in the magnitude of the stored energy in both modes over time. A small observable difference exists for the value of stored energy in both modes. However, mod2 remained longer in a fairly constant energy storage region than mod1. This is because since mod 2 functioned at a greater temperature compared to mod 1 when the HTF inlet temperature rises, there is an increase of sensible heat in capsules and the rate of transfer of heat from the HTF to the PCM which is linearly related to the difference in temperature between the air and the PCM is enlarged thus enhancing the heat transfer coefficient.

Figure 8 also depicts the representative variation of accumulated power over time for the two modes. It can be seen that a simple straight-line relationship exists between the accumulated heat and charging time during the charging cycle. The observed tendency can be elucidated by the approximately continuous PCM melting rate. A similar trend was gotten by Liu et al. [10] in his experimental study involving PCM and water as HTF. Mod2 has a sloppier graph and therefore has a greater accumulated heat per time. This is because since $\bmod 2$ operated at a 
higher temperature, as the temperature of the HTF increases, the charging rate increases understandably due to the increase in the sensible heat in capsules thus making the charging time to reduce[61].

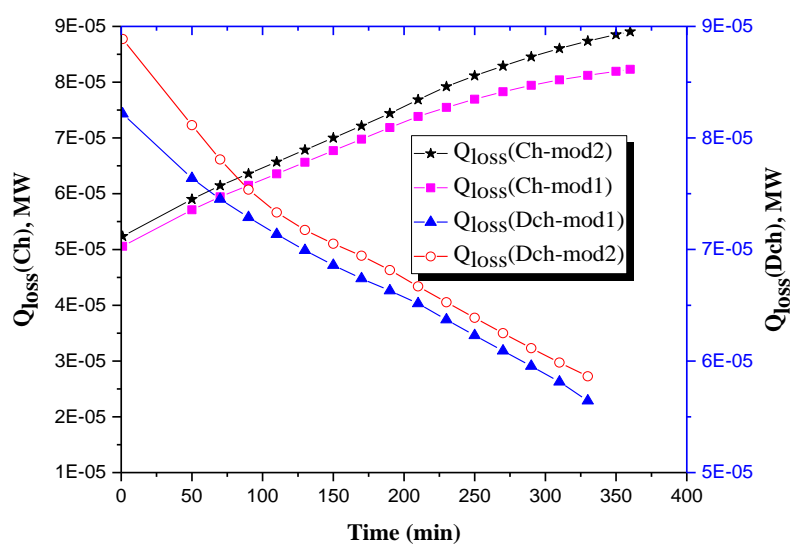

Figure 9: Heat loss during charging and discharging mode

Moreover, the higher temperature of the HTF in mod2 enhances the heat transfer coefficient leading to the observed higher accumulated heat per time in comparison to mod1.

\subsection{Discharging mode general discharging behaviour}

In the discharge phase, the mode of travel of the HTF is inverted. The HTF arrives from the bottom of the TEST and departs from the top. At the commencement of the discharging operation, the PCMs in the three segments of the TEST are all in the liquid phase and so, the overall thermal conductivity of the PCM is enhanced greatly by the natural convection features in the liquid PCM. Through the uninterrupted flow of the cold HTF over the PCMs from the bottom and out through the top, the PCM capsules in the TEST bottom discharge their heat to the HTF slowly till after some minutes when the PCMs in the bottom portion begins to solidify partially while those at the mid and top segments continue to remain in liquid state. As the charging time progresses, more of the PCMs in the other segments of the TEST take part in solidification. The dynamics of the solidification curves in each segment of the TEST during the discharging operation in the two modes studied in this research can be divided into three main phases. The first phase is the cooling phase. It is characterised by a rapid reduction in the temperature of the PCM to its solidification point and the transfer of energy from the PCMs to the cold compressed air is by sensible heat only. The heat recovered by the HTF is thus, primarily the sensible heat of the liquid PCM [10]. Immediately after the cooling phase is the quasi-isothermal latent heat stage phase called solidification phase. In this phase, the PCM temperature remains nearly constant due to latent heat transfer. The last phase is the subcooling phase where again, only sensible heat transfer takes place and the temperature of the PCM decreases sharply to its final lowest temperature. Figure $10(\mathrm{a}-\mathrm{c})$ show the temperature histories of the PCM at three axial locations $\left(x=1, x=0.25 \mathrm{~L}_{\mathrm{s}}\right.$ and $\left.\mathrm{x}=0.5 \mathrm{~L}_{\mathrm{s}}\right)$ in each of the three segments of the TEST, namely, bottom segment (Bs), middle segment (Ms) and top segment (Ts) packed with different PCMs and each with length of segment $\left(\mathrm{L}_{\mathrm{s}}\right)$ equivalent to one third the height of the TEST $\left(\mathrm{L}_{\mathrm{s}}=\mathrm{H}_{\mathrm{TEST}} / 3\right)$.

As can be perceived from Figure 10a, the first sensible heat phase for the PCMs at the Bs of the TEST is very short and a considerable quantity of energy discharge proceeds at a constant 
temperature during the phase change. After about 10 minutes, the PCMs at the entrance $(x=1)$ solidifies totally in both modes. This can be elucidated by the high-temperature difference between the PCM and the HTF at the bottom section of the TEST. The temperature profile at the middle (Ms) and bottom (Bs) sub-segments of the three segments of the TEST is shown in Figure $10 \mathrm{~b}$ and $\mathrm{c}$. Notice that for the same axial distance $(\mathrm{x}=1)$ it takes more time for the PCM to solidify in the middle (Ms) and top (Ts) segments of the TEST. Whereas the PCM solidifies nearly the instant the discharging operation commences in the bottom segment of the TEST (Figure 10a), it takes around 175 minutes for the PCM to solidify fully in the middle segment of the TEST at $\mathrm{x}=1$ while in the top segment, it takes around 225 minutes for the PCM to be totally solidified at the same axial location $(\mathrm{x}=1)$. The reason for this is as the HTF temperature increases continuously as it travels from the bottom of the TEST to the exit.

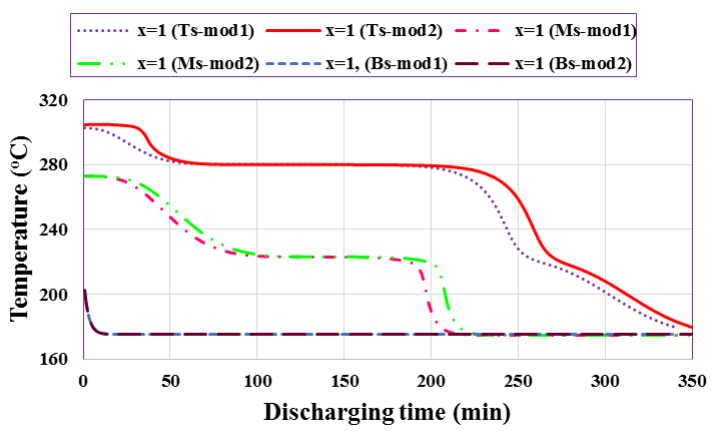

(a)

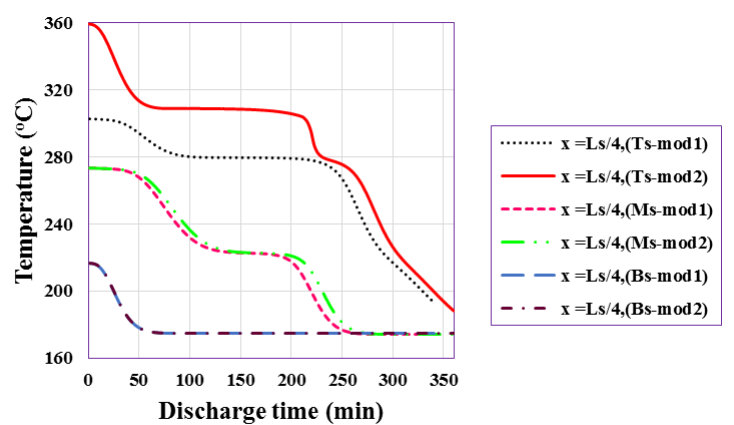

(b)

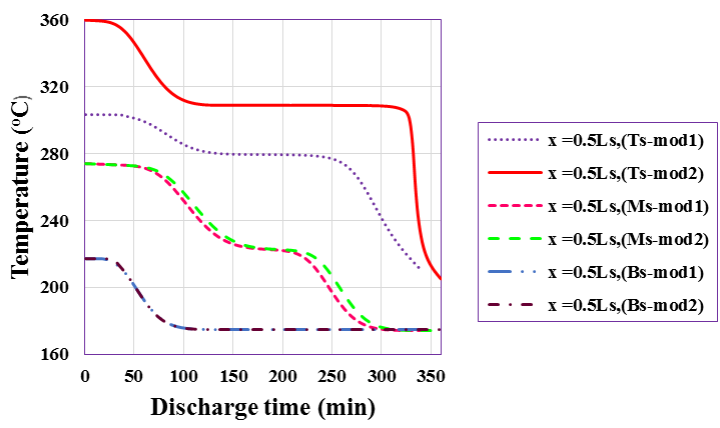

(c)

Figure 10: Outlet temperature of PCM during discharge mode (a) Top section (Ts), $x=1$ (b) Middle section, $\mathrm{x}=0.25 \mathrm{Ls}(\mathrm{Ms})(\mathrm{c})$ Bottom section (Bs), $\mathrm{x}=0.5 \mathrm{Ls}$

The increasing temperature consequently results in a consecutive reduction in temperature difference between the PCM and the HTF causing reduction in the charging energy and thus increment in solidification time. In the temperature profile at the middle for the three segments of the TEST, as shown in Figure 10b, using the temperature features at the bottom segment (Bs) as an example, dissimilar to the temperature characteristics at the bottom in Figure 10a, it can be seen that the first sensible heat discharging stage is very noticeable and the change of phase stage takes place much later, at about 50 minutes (in both modes) compared to the bottom section in Figure 10a. Also observe that the discharging rate in the middle segment of the TEST is somewhat lower than at the bottom sub-section. At $\mathrm{x}=1 / 4 \mathrm{Ls}$ in Ms of the TEST (Figure 10b), approximately 250 minutes is needed in mod1 and 265 minutes in mod2 for the PCM to be totally discharged. This is in dissimilarity to lesser discharging time of 210 and 225 minutes at the Ms of the bottom segment (Figure 10c). Although the difference between the discharging 
time is almost the same for the two modes at Ms, $\mathrm{x}=1 / 4$ Ls (Figure 10b), and Ms, $\mathrm{x}=0.5 \mathrm{Ls}$ (Fig 10.c), mod 2 has a higher discharge time because during the charging mode, it stayed longer in the constant temperature phase change region than mod1 owing to its higher temperature and thus possess more energy in the latent heat region compared to mod1. It is pertinent to note that in all the sections of the TEST, the decreasing rate of the PCM temperature is fastest in the first sensible heat phase than in the other phases. This is since the sensible heat is much smaller than the latent heat.

The same tendency seen in the Ts and Ms of the TEST segments is also witnessed in the Bs as can be seen in Figure 10c At axial distance corresponding to half the length of each TEST segment $(\mathrm{x}=0.5 \mathrm{Ls})$, the discharge time for the PCM rose to about $300 \mathrm{~min}$ for $\bmod 1$ and 310 minutes for mod 2 at Ms. It is fascinating to note that at the top segment (Ts) of the TEST, mod2 took a smaller time to start melting than mod1. This can be explained by the higher temperature difference and hence greater rate of heat transfer in $\bmod 2$ owing to its higher final charge state temperature of about $360{ }^{\circ} \mathrm{C}$ compared to about $320{ }^{\circ} \mathrm{C}$ for mod1. One of the motives for embarking on this study is to find out which has more effect on the performance of A-CAES TEST system between mod 1 with lower temperature and greater flow rate or mod 2 with higher temperature and lower flow rate. While both high mass flow rate and high temperature have been established to improve the performance of a TEST system by decreasing the melting time of the PCMs $[10,13]$, the fallouts of the analysis implemented in this research suggest that temperature has a much dominant influence than the flow rate. This could be explained thus; from basic convective heat transfer theory, it is acknowledged that high mass flow rate of the HTF can only improve the convective heat transfer between the hot CA and the inside wall of the TEST and according to Liu et al. [10], the thermal resistance of this process of convective heat transfer is of inconsequential value when compared to the thermal conduction resistance of the PCM owing to the very low thermal conductivity of the PCM [61].

Also, for spherical particles of the cylindrical arrangement, the coefficient of heat transfer due to convection is in direct proportion to the $\mathrm{n}^{\text {th }}$ power of the flow rate, where $\mathrm{n}$ is a constant between 0.3 and 0.8 . This additionally plays a part to the insignificant effects of the high mass flow rate of the HTF in mod1 [61].

\subsection{Energy and exergy efficiency}

The plot of the variation in energy and exergy efficiency (EnEff, ExEff) during charging for the two modes is shown in Figure 11. The results obtained shows that the performance of the two modes differs a lot from energy analysis to exergy analysis. Analogous to the trend of the stored energy, the energy and exergy efficiency for the two modes is high and fairly stable at first and reduced fairly at a constant rate with time as the charging proceeded. The EnEff varies from 97.6 to $96.7 \%$ with a mean value of $97 \%$ in mod1. In mod2, EnEff changes from 98.3 to $97.8 \%$ with a mean of $98 \%$. Again mod 2 has a mean energy efficiency that is greater than that of mod 1. However, the variation in energy efficiency in both modes is small and below $3 \%$. The efficiency values reported for the two modes above is within the range of characteristic values reported in the literature. Precisely Peng et al. [48] reported charging energy efficiency values that vary from 98.5 to $96 \%$ for a PCM based TES packed bed with a height of $5 \mathrm{~m}$, Diameter of $1 \mathrm{~m}, \mathrm{HTF}$ temperature of $400^{\circ} \mathrm{C}$ and temperature of PCM when cold of $250^{\circ} \mathrm{C}$.

The calculated exergy efficiency varies from 69.6 to $53.3 \%$ in mod 1 with a mean value of $65 \%$. In mod2, the exergy efficiency varied from 74.3 to $61 \%$ with a mean value of $72 \%$. A percentage variation of exergy efficiency of $7.2 \%$ is calculated for mod 1 and $3.5 \%$ for $\bmod 2$. 
The lesser variation in energy efficiency in $\bmod 2$ could be attributed to the lengthier phase change temperature observed in mod2. Greater energy efficiency in mod2 suggests a greater quantity of heat is charged into the TEST in mod 2 compared to mod1. The exergy efficiency values as reported above are within the range reported by other researchers. Elfeky et al. [76] reported exergy efficiency of $75.2 \%$ for a three-stage PCM TEST in their study on numerical comparison between single and multi-stage PCM based high-temperature TES for CSP tower plants [61]. Appraisal of the energy and exergy efficiency results of both modes suggests that the energy efficiency is permanently more than the exergy efficiency. This is expected since the entire energy content of the charging $\mathrm{CA}$ is accounted for in the estimation of energy efficiency. In other words, to evaluate the energy efficiency, the quality of the energy transferred is neglected while the quantity of energy transferred is taken into account but in exergy efficiency valuation, the quality of the available energy extracted from the CA air is accounted for and this quality degrade over time due to thermal exergy loss resulting from internal irreversibility[61].

Since mod 2 operated lengthier in the stable constant efficiency region than mod1, it implies that in applications requiring a longer and efficient stable operation, mod 2 will be favoured since it is apparent that mod 2 can warrant a more uniform outlet energy and exergy efficiency than mod1. The variation in the energy efficiency for the two modes over the charging time analysed is insignificant and below 5\% additionally buttressing the benefit of a LH TES system to provide a relatively constant efficiency over its operating cycle.

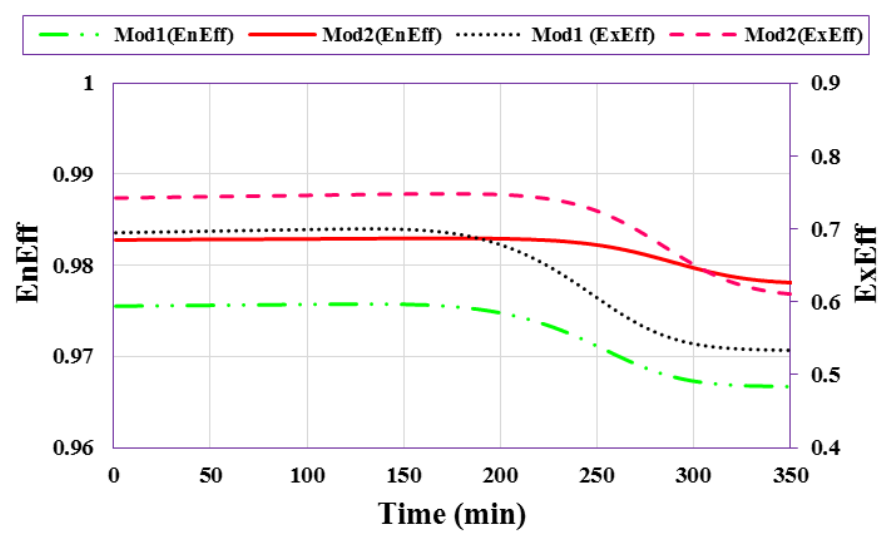

Figure 11: Energy and exergy efficiency of charging mode

Figure 12 displays the plot of energy (EnEff) and exergy (ExEff) efficiency for the two modes analysed during the recovery cycle. Both parameters exhibit a comparable trend with the charging mode but on a lesser scale. Once more, mod2 has a higher EnEff than mod1. The values of computed energy efficiency for mod 1 varied from $87-77 \%$ with a mean value of $78 \%$. For mod2, energy efficiency varies from $97-79 \%$ with a mean value of $80 \%$ over the same charging period. The values of the discharging efficiency for the two modes fall in range with reported values in similarly published works. Wu et al. [27] reported discharging efficiencies of 98.3 and $94.8 \%$ for capsule diameters of 0.02 and $0.04 \mathrm{~m}$ at discharging time of 5.57 and 5.37 hours respectively. As anticipated, the exergy efficiency is below the energy efficiency and varies from $66-60 \%$ in $\bmod 1$ and $74-69 \%$ in $\bmod 2$ with average values of 66 and $68 \%$ respectively. 


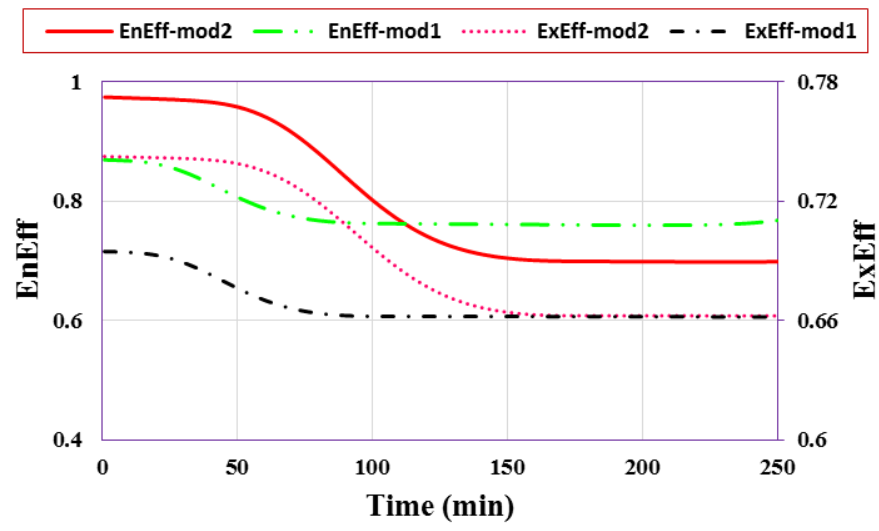

Figure 12 : Energy and exergy efficiency of discharging mode

Figure 13 displays the variation of RTE and overall exergy efficiency (ExEo) for the two modes. The RTE for both modes varies just like the charging and discharging energy efficiencies. The RTE of mod1 varied from $87-77 \%$ with a mean value of $76 \%$ whereas that for mod 2 varies from $97-79 \%$ with a mean value of $78 \%$. Again, the values of the RTE are comparable to mean values of 77,84 and $86 \%$ reported by Li et al. [13] to be the overall energy efficiency in their experimental investigation of the impact of various HTF temperatures of 425,445 , and $465{ }^{\circ} \mathrm{C}$ at a constant mass flow rate of $260 \mathrm{~kg} / \mathrm{h}$ on the performance of a PCM based thermal energy storage tank.

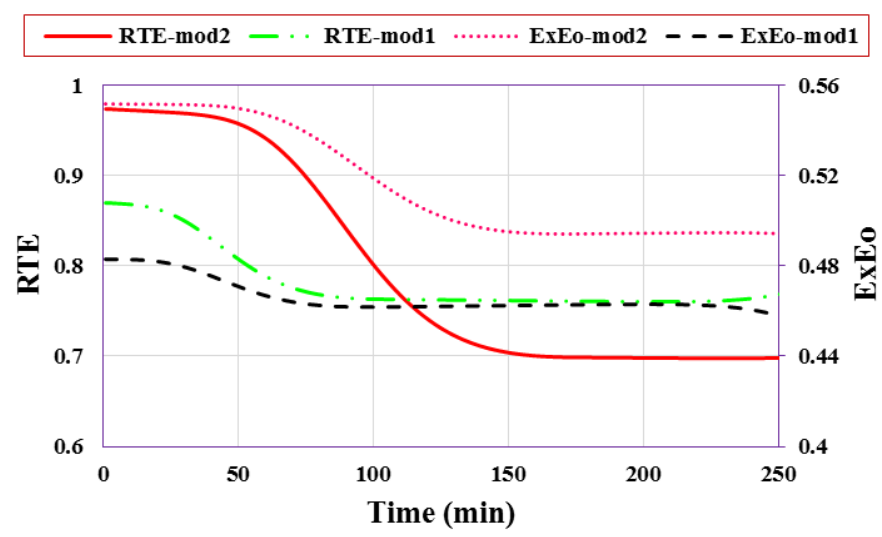

Figure 13: Overall energy and exergy efficiency

Likewise, the overall exergy efficiency varies from $0.48-0.33$ in mod 1 and $0.55-0.44$ in $\bmod 2$ with average values of 0.45 and 0.51 in $\bmod 1$ and $\bmod 2$ respectively.

\subsection{Parametric analysis results}

The influence of key parameters used in the model on the performance of the TEST charging and discharging performance was examined. This section reports the results obtained.

\subsubsection{Influence of packing height}

The effect of the different PCM arrangement options considered in the sensitivity analysis on the performances of the two modes during charging are presented in terms of the energy efficiency, exergy efficiency and temperature profile of the PCM at the same TEST subsegment height of $2 L_{s} / 3$, as shown in Figure 14 and Figure 15 respectively for the charging 
mode. The PCM temperature profile shows the rate of melting or freezing of the PCMs in the TEST. The slope of the curve signifies how quick the rate of charging and discharging cycle is. Sharper slope means a better dynamic performance of the system. Energy efficiency measures the rate of energy transfer and the exergy efficacy indicates the quality of energy transfer and recovery. As can be observed from Figure 14, increasing the length of tank occupied by the PCMs (from the top to the bottom) results in shorter isothermal phase change period for the surface temperature of the PCM and hence the melting point. From Figure 14, it can be observed that the order of PCM melting time from the lowest to the highest is Ar2, Ar3, and Ar1 respectively. This is because Ar2 has the highest number of PCMs with high melting temperature in the Ts and Ms of the TEST while Ar1 has the least. A large amount of energy storage takes place during the phase change period [77]. PCM2 and PCM3 has the highest latent heat value of the three PCMs considered in that order and since Ar2 has the highest number of PCMs with high latent heat in the Ts and Ms of the TEST where the compressed air temperature is still high, the charge time decreases because of increases in sensible energy extraction rate as a result of more heat transfer interfacial area for thermal energy extraction and subsequent storage by the PCM.

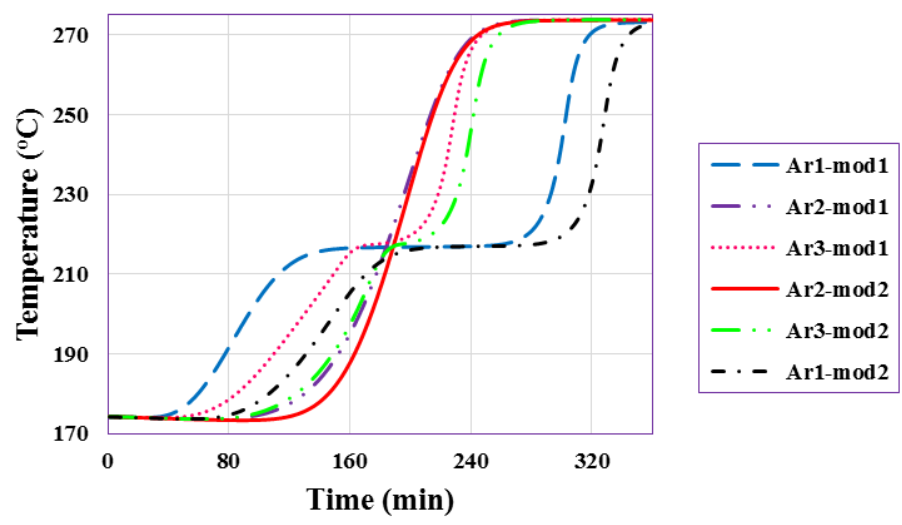

Figure 14: Temperature profile of PCM at height of $2 L_{s} / 3$

Figure 15 (a) and (b) compares the average energy and exergy efficiency of the different arrangements with that of the base case designs using the PCMs involved during the charging process. The results are obtained at the same charging times for all cases. During the charging process, Ar2-mod2, attains the highest energy and exergy efficiency followed by the base case $\bmod 2$. The worst performance is exhibited by Ar1-mod1. The observed trend again can be directly linked with the arrangement and thermo-physical properties of the PCMs, plus the inlet temperature of the HTF. Due to the high temperature of HTF in Ar2-mod2 and since Ar2 has the largest quantity of PCMs with high latent heat in the Ts and Ms of the TEST where the temperature of the CA is still high, there is a high energy transfer rate between the HTF and the PCM which was enough to cause complete melting of all the PCMs thus accounting for the best performance recorded. Thus correct arrangement of PCM packing height is critical. However, for the AR1-mod1 with the poorest performance, the PCMs occupying the bottom of the TEST took a lengthier time to melt due to the twin reason that the HTF temperature is low and also the AR1-mod1 has smallest quantity of PCMs with high latent heat in the Ts and Ms of the TEST. Consequently, there is a smaller change in temperature between the PCM and HTF resulting to lower charging rate. 


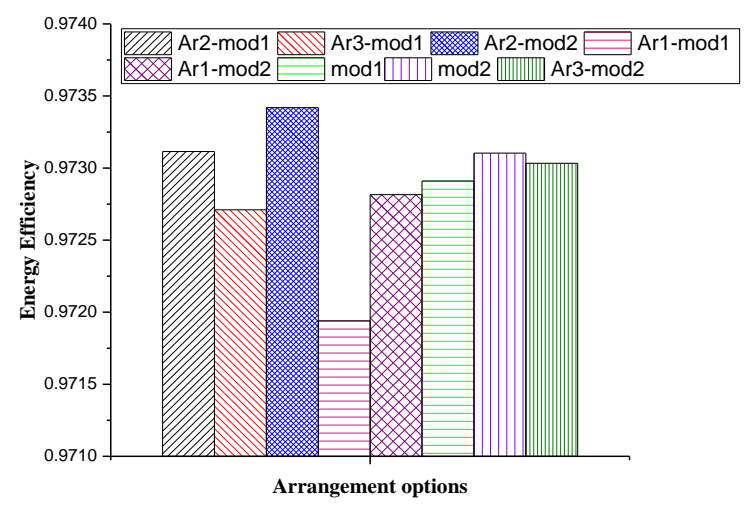

(a)

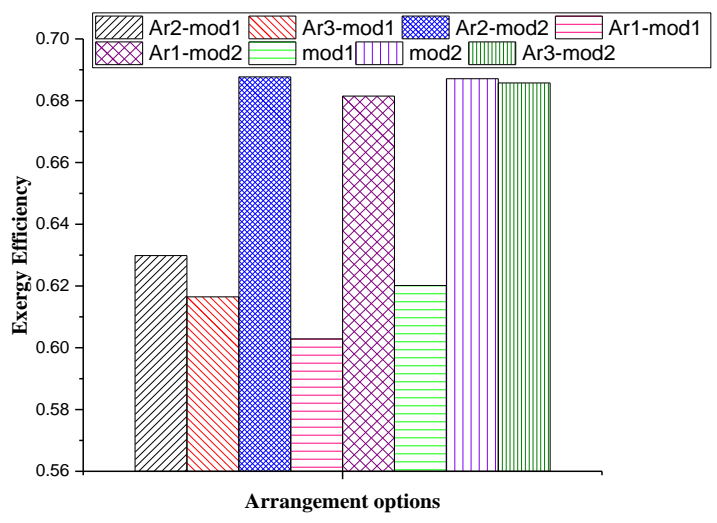

(b)

Figure 15: Energy and Exergy efficiency for various arrangements

\subsubsection{Effects of number of multiple PCM}

The thermal performance of a LH TEST system has been established to increase with multi PCM configuration [77]. In this study, two and three PCM multiple configuration arrangement options were analysed in the parametric analysis to study their influence on the performance of the two charging modes analysed. The thermal performances of multiple PCM arrangements are presented in terms of the accumulated stored energy (Qac), round trip efficiency (RTE) and overall exergy efficiency (ExEo).

Figure 1 displays the accumulated stored energy $\left(\mathrm{Q}_{\mathrm{ac}}\right)$ for the $2 \mathrm{PCM}$ and 3-PCM mixture studied. In Figure 16, the following possibilities were considered: the 2-PCM (mod1 and $\bmod 2)$ arrangement and, 3-PCM (mod1 and mod2) arrangement. The 3-PCM arrangement is the reference case analysed in the thesis. In the 2-PCM case, the TEST is filled with PCM1 and PCM2 capsules with PCM1 on top and PCM2 below in the direction of the charging HTF. Concerning Figure 16, the slope of the line indicates how low or fast the charging rate is with sharper slopes signifying better dynamic performance of the system [77].

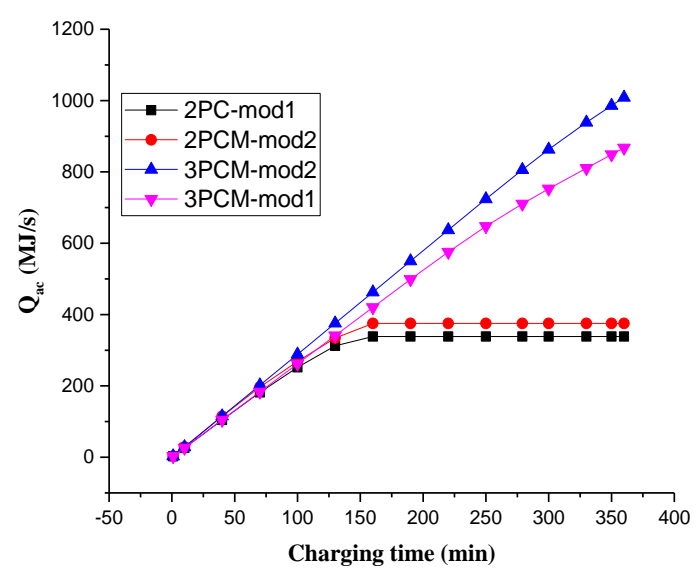

Figure 16: Accumulated stored energy of 3PCM vs. 2PCM 
From Figure 16, it can be observed that that, the accumulated energy vs. time presents a straight-line relationship within the charging period for 3-PCM arrangement. However, the accumulated energy in 2 PCM arrangement becomes constant after about 150 minutes while that for the 3 PCM arrangement continues to be linear with time. The three-stage PCMs case achieves the high performance since it has the best matching melting temperature distribution with the temperature profile of HTF [77]. In a 3 multiple PCMs arrangement, the three PCMs are arranged in decreasing order of melting points and the melting temperature of the last PCM is low $\left(220^{\circ} \mathrm{C}\right)$ and the HTF leaves each PCM interface at a temperature very near to the melting temperature of the lower PCM. Each of the lower PCM can exploit the exergy contained by the incoming flow stream to fast-track the phase transition process, thus stimulating superior usage of latent heat as well as sensible heat [76,77]. Thus the 3 PCM arrangement maintains a higher nearly constant PCM melting rate, especially in the later period of the charging process [10]. Whereas, in the 2 multiple PCM arrangements, the melting temperature of the last PCM (PCM2) in this instance is high $\left(277^{\circ} \mathrm{C}\right)$ which lead to less temperature difference between the PCM and the incoming HTF, and thus less heat flow driving force. After about 150 minutes in the charging cycle, most of the PCMs has undergone a change of phase, and shortly afterwards, the charging cut-off temperature is attained thus making the accumulated energy to remain constant.

Figure 17 shows the RTE (a) and ExEo (b)) of the two options. From Figure 17 (a), the result shows that the mod2- 3PCM arrangement has the highest RTE with an average efficiency of $87.5 \%$.

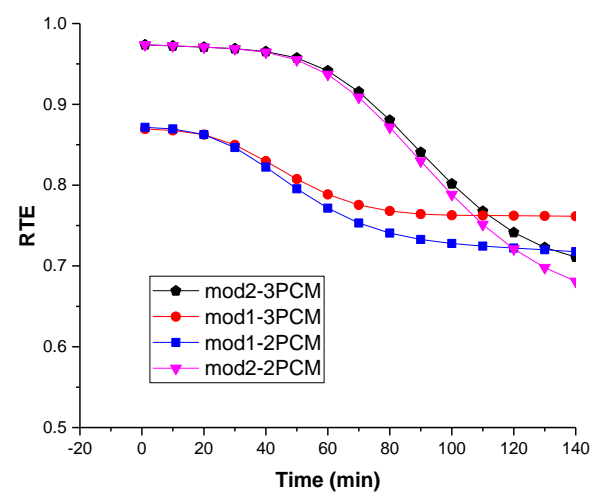

(a)

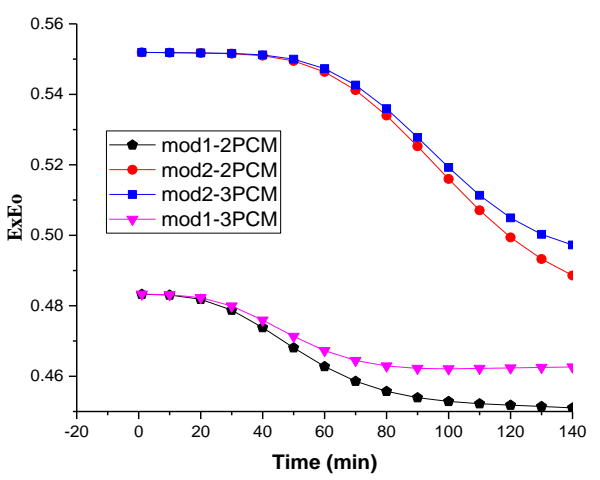

(b)

Figure 17: Energy efficiency and Exergy efficiency of 3PCM vs. 2PCM

Arrangement mod2-2PCM is the second-best in performance with an average RTE of $86.5 \%$ while the mod1-2PCM arrangement has the lowest energy efficiency performance with an average RTE of about $70.1 \%$. Although the RTE of mod2-2PCM arrangement is close to that of mod2-3PCM, the variation of energy efficiency over the charging period is more pronounced in 2PCM arrangement than in 3PCM arrangement. Mod2-2PCM arrangement varied by about $30.1 \%$ from a maximum value of $97.4 \%$ at the beginning of charging operation to a minimum value of $68.1 \%$ whereas mod2-3PCM arrangement varied by about $26.9 \%$ from the same maximum value as mod2-3PCM to a minimum value of $71.1 \%$. The reason for the observed better stable operation of mod2-3PCM Ar is because of the more uniform accumulated stored energy in mod2-3PCM due to higher nearly constant PCM melting rate, especially in the later period of the charging process compared to 2 PCM arrangement. Moreover, the melting temperature distribution in $3 \mathrm{PCM}$ arrangement matches the heat transfer temperature profile 
better than in the $2 \mathrm{PCM}$ arrangement. This improves the heat transfer process and increases the system dynamic performance [77].

The corresponding overall exergy efficiency is as shown in Figure 1 (b). For all of the options, the exergy and energy efficiency decreases negligibly during the initial period of the charging process because of the very fast increase in the temperature of the PCM from its sensible state to the mushy region where it stayed much longer as it extracts energy from the HTF. As the charging progresses, the PCM is completely, melted and its temperature approaches the inlet temperature of the HTF and thus the temperature difference between the PCM and HTF reduces, leading to a reduction in the ExEo of the systems. Furthermore, mod2 3-PCM arrangement has almost the same ExEo value of about $53.0 \%$ as mod2 2-PCM arrangement. However, the variation of exergy efficiency over the charging/discharging time is higher in $\bmod 2-2 \mathrm{PCm}(11.5 \%)$ compared to the variation of $9.39 \%$ estimated in $\bmod 2-3 \mathrm{PCM}$. The mod1-2PCM still has the least exergy efficiency performance.

\subsection{Conclusions}

A numerical model was developed to compare two charging modes of a thermal energy storage tank (TEST) system for adiabatic compressed air energy storage system (A_CAES) employing a multi-PCM system. Numerical results indicate that Mod 2 with higher temperature and lower mass flow rate is better in performance than mod1 with higher mass flow rate and lower temperature in both the charging and discharging cycle. This is so because the temperature has a much more dominant influence in heat transfer than the mass flow rate

The specific results obtained are summarised as follows:

- The average net energy efficiency of the TEST is approximately 97 and $98 \%$ in mod 1 and mod 2 respectively during the charging periods. On the other hand, the average exergy efficiency is found to be 65 and $72 \%$ for mod 1 and mod 2 respectively.

- The round trip efficiency varied from a maximum value of $87 \%$ in mod 1 and $0.97 \%$ in mod2 to a minimum value of $77 \%$ in $\bmod 1$ and $79 \%$ in $\bmod 2$ respectively. This translates to average efficiencies of 78 and $80 \%$ for $\bmod 1$ and $\bmod 2$ respectively

- The overall exergy efficiency varied from a maximum value of 48 and $55 \%$ to the minimum value of 33 and $44 \%$ in $\bmod 1$ and $\bmod 2$ respectively. This translates to an average efficiencies of 45 and $51 \%$ in mod 1 and $\bmod 2$ respectively.

- Results of a parametric analysis on the influence of the number of multiple systems on the performance of the system shows that that correct arrangement of PCM packing height is critical. Expectedly that the $3-\mathrm{PCM}$ arrangement can store and discharge more energy than 2 PCM arrangement. The mod2 3PCM arrangement has the highest RTE with an average efficiency of $87.5 \%$. Arrangement mod2-2PCM is the secondbest in performance with an average RTE of $86.5 \%$ while the mod1-2PCM arrangement has the lowest energy efficiency performance with an average RTE of about $70.1 \%$.

- Also, parametric analysis on the arrangement of the three PCMs in the TEST shows that due to the thermal properties of PCM1 and PCM2 and the larger temperature difference experienced during the charging process, the mod2-3PCM Ar2 has the highest energy and exergy efficiency and stores more energy.

- The smaller temperature difference between the HTF and the PCM in mod1-AR1 coupled with the low values of latent heat leads to the system having the worst performance of the arrangement options considered. 


\section{Acknowledgement}

The authors acknowledge the $\mathrm{PhD}$ scholarship received from Tertiary Education Trust Fund, Nigeria through Enugu State University of Science and Technology (ESUT) for their PhD research.

\section{Declarations of competing interest: None}

References

[1] Li G, Zheng X. Thermal energy storage system integration forms for a sustainable future. Renew Sustain Energy Rev 2016;62:736-57. doi:https://doi.org/10.1016/j.rser.2016.04.076.

[2] Li G. Energy and exergy performance assessments for latent heat thermal energy storage systems. Renew Sustain Energy Rev 2015;51:926-54. doi:https://doi.org/10.1016/j.rser.2015.06.052.

[3] Li G. Sensible heat thermal storage energy and exergy performance evaluations. Renew Sustain Energy Rev 2016;53:897-923.

[4] Li G. Organic Rankine cycle performance evaluation and thermoeconomic assessment with various applications part I: Energy and exergy performance evaluation. Renew Sustain Energy Rev 2016;53:477-99. doi:https://doi.org/10.1016/j.rser.2015.08.066.

[5] Aneke M, Wang M. Process analysis of pressurized oxy-coal power cycle for carbon capture application integrated with liquid air power generation and binary cycle engines. Appl Energy 2015;154:556-66. doi:http://dx.doi.org/10.1016/j.apenergy.2015.05.030.

[6] Olumayegun O, Wang M, Oko E. Thermodynamic performance evaluation of supercritical CO 2 closed Brayton cycles for coal-fired power generation with solventbased CO 2 capture. Energy 2019. doi:10.1016/j.energy.2018.10.127.

[7] Diyoke C. A new approximate capacity factor method for matching wind turbines to a site: case study of Humber region, UK. Int J Energy Environ Eng 2019:1-12. doi:10.1007/s40095-019-00320-5.

[8] Diyoke $\mathrm{C}, \mathrm{Wu} \mathrm{C}$. Thermodynamic analysis of hybrid adiabatic compressed air energy storage system and biomass gasification storage (A-CAES + BMGS) power system. Fuel 2020;271:117572. doi:https://doi.org/10.1016/j.fuel.2020.117572.

[9] Gong Z-X, Mujumdar AS. Cyclic heat transfer in a novel storage unit of multiple phase change materials. Appl Therm Eng 1996;16:807-15. doi:http://dx.doi.org/10.1016/1359-4311(95)00088-7.

[10] Liu Z, Wang Z, Ma C. An experimental study on heat transfer characteristics of heat pipe heat exchanger with latent heat storage. Part I: Charging only and discharging only modes. Energy Convers Manag 2006;47:944-66. doi:https://doi.org/10.1016/j.enconman.2005.06.004.

[11] Nallusamy N, Sampath S, Velraj R. Experimental investigation on a combined sensible and latent heat storage system integrated with constant/varying (solar) heat sources. Renew Energy 2007;32:1206-27. doi:http://dx.doi.org/10.1016/j.renene.2006.04.015.

[12] Peng H, Li R, Ling X, Dong H. Modeling on heat storage performance of compressed air in a packed bed system. Appl Energy 2015;160:1-9. doi:http://dx.doi.org/10.1016/j.apenergy.2015.09.029.

[13] Li M-J, Jin B, Ma Z, Yuan F. Experimental and numerical study on the performance of a new high-temperature packed-bed thermal energy storage system with macroencapsulation of molten salt phase change material. Appl Energy 2018;221:115. doi:https://doi.org/10.1016/j.apenergy.2018.03.156.

[14] Felix Regin A, Solanki SC, Saini JS. An analysis of a packed bed latent heat thermal 
energy storage system using PCM capsules: Numerical investigation. Renew Energy 2009;34:1765-73. doi:http://dx.doi.org/10.1016/j.renene.2008.12.012.

[15] Al-Abidi AA, Mat S, Sopian K, Sulaiman MY, Mohammad AT. Experimental study of melting and solidification of PCM in a triplex tube heat exchanger with fins. Energy Build 2014;68:33-41. doi:https://doi.org/10.1016/j.enbuild.2013.09.007.

[16] Bhagat K, Saha SK. Numerical analysis of latent heat thermal energy storage using encapsulated phase change material for solar thermal power plant. Renew Energy 2016;95:323-36. doi:https://doi.org/10.1016/j.renene.2016.04.018.

[17] Wu S, Fang G. Dynamic performances of solar heat storage system with packed bed using myristic acid as phase change material. Energy Build 2011;43:1091-6. doi:https://doi.org/10.1016/j.enbuild.2010.08.029.

[18] Barbour E, Mingnard D, Ding Y, Li Y. Adiabatic Compressed air Energy storage with packed bed thermal energy storage. Appl Energy 2015;155:804-15.

[19] Tessier MJ, Floros MC, Bouzidi L, Narine SS. Exergy analysis of an adiabatic compressed air energy storage system using a cascade of phase change materials. Energy 2016;106:528-34. doi:http://dx.doi.org/10.1016/j.energy.2016.03.042.

[20] Rady M. Granular phase change materials for thermal energy storage: Experiments and numerical simulations. Appl Therm Eng 2009;29:3149-59. doi:http://dx.doi.org/10.1016/j.applthermaleng.2009.04.018.

[21] Xia L, Zhang P, Wang RZ. Numerical heat transfer analysis of the packed bed latent heat storage system based on an effective packed bed model. Energy 2010;35:202232. doi:http://dx.doi.org/10.1016/j.energy.2010.01.018.

[22] Karthikeyan S, Velraj R. Numerical investigation of packed bed storage unit filled with PCM encapsulated spherical containers - A comparison between various mathematical models. Int J Therm Sci 2012;60:153-60. doi:http://dx.doi.org/10.1016/j.ijthermalsci.2012.05.010.

[23] Amin NAM, Belusko M, Bruno F, Liu M. Optimising PCM thermal storage systems for maximum energy storage effectiveness. Sol Energy 2012;86:2263-72. doi:https://doi.org/10.1016/j.solener.2012.04.020.

[24] Zhao W, Elmozughi AF, Oztekin A, Neti S. Heat transfer analysis of encapsulated phase change material for thermal energy storage. Int J Heat Mass Transf 2013;63:323-35. doi:https://doi.org/10.1016/j.ijheatmasstransfer.2013.03.061.

[25] Al-Abidi AA, Mat S, Sopian K, Sulaiman MY, Mohammad AT. Numerical study of PCM solidification in a triplex tube heat exchanger with internal and external fins. Int J Heat Mass Transf 2013;61:684-95. doi:https://doi.org/10.1016/j.ijheatmasstransfer.2013.02.030.

[26] Peng H, Dong H, Ling X. Thermal investigation of PCM-based high temperature thermal energy storage in packed bed. Energy Convers Manag 2014;81:420-7. doi:http://dx.doi.org/10.1016/j.enconman.2014.02.052.

[27] $\mathrm{Wu} \mathrm{M}, \mathrm{Xu} \mathrm{C}, \mathrm{He} Y-\mathrm{L}$. Dynamic thermal performance analysis of a molten-salt packed-bed thermal energy storage system using PCM capsules. Appl Energy 2014;121:184-95. doi:http://dx.doi.org/10.1016/j.apenergy.2014.01.085.

[28] Aldoss TK, Rahman MM. Comparison between the single-PCM and multi-PCM thermal energy storage design. Energy Convers Manag 2014. doi:10.1016/j.enconman.2014.03.047.

[29] Bellan S, Alam TE, González-Aguilar J, Romero M, Rahman MM, Goswami DY, et al. Numerical and experimental studies on heat transfer characteristics of thermal energy storage system packed with molten salt PCM capsules. Appl Therm Eng 2015;90:970-9. doi:https://doi.org/10.1016/j.applthermaleng.2015.07.056.

[30] Izquierdo-Barrientos MA, Sobrino C, Almendros-Ibáñez JA. Modeling and 
experiments of energy storage in a packed bed with PCM. Int J Multiph Flow 2016;86:1-9. doi:https://doi.org/10.1016/j.ijmultiphaseflow.2016.02.004.

[31] Dadollahi M, Mehrpooya M. Modeling and investigation of high temperature phase change materials (PCM) in different storage tank configurations. J Clean Prod 2017. doi:10.1016/j.jclepro.2017.05.171.

[32] Pakrouh R, Hosseini MJ, Ranjbar AA, Bahrampoury R. Thermodynamic analysis of a packed bed latent heat thermal storage system simulated by an effective packed bed model. Energy 2017;140:861-78. doi:https://doi.org/10.1016/j.energy.2017.08.055.

[33] Pirasaci T, Wickramaratne C, Moloney F, Goswami DY, Stefanakos E. Influence of design on performance of a latent heat storage system at high temperatures. Appl Energy 2018;224:220-9. doi:https://doi.org/10.1016/j.apenergy.2018.04.122.

[34] Wang Y, Yu K, Ling X. Experimental and modeling study on thermal performance of hydrated salt latent heat thermal energy storage system. Energy Convers Manag 2019. doi:10.1016/j.enconman.2019.111796.

[35] Mehta DS, Solanki K, Rathod MK, Banerjee J. Thermal performance of shell and tube latent heat storage unit: Comparative assessment of horizontal and vertical orientation. J Energy Storage 2019;23:344-62. doi:https://doi.org/10.1016/j.est.2019.03.007.

[36] Khan Z, Khan ZA. Thermodynamic performance of a novel shell-and-tube heat exchanger incorporating paraffin as thermal storage solution for domestic and commercial applications. Appl Therm Eng 2019;160:114007. doi:https://doi.org/10.1016/j.applthermaleng.2019.114007.

[37] Lee YT, Kim MH, Lee SS, Gim J, Chung JD. Numerical analysis in a full-scale thermal energy storage tank with dual PCM capsules. Energy Build 2019;204:109410. doi:https://doi.org/10.1016/j.enbuild.2019.109410.

[38] Mao Q, Zhang Y. Thermal energy storage performance of a three-PCM cascade tank in a high-temperature packed bed system. Renew Energy 2020;152:110-9. doi:https://doi.org/10.1016/j.renene.2020.01.051.

[39] Guerraiche D, Bougriou C, Guerraiche K, Valenzuela L, Driss Z. Experimental and numerical study of a solar collector using phase change material as heat storage. J Energy Storage 2020;27:101133. doi:https://doi.org/10.1016/j.est.2019.101133.

[40] Pu L, Zhang S, Xu L, Li Y. Thermal performance optimization and evaluation of a radial finned shell-and-tube latent heat thermal energy storage unit. Appl Therm Eng 2020;166:114753. doi:https://doi.org/10.1016/j.applthermaleng.2019.114753.

[41] Ahmed N, Elfeky KE, Lu L, Wang QW. Thermal performance analysis of thermocline combined sensible-latent heat storage system using cascaded-layered PCM designs for medium temperature applications. Renew Energy 2020. doi:https://doi.org/10.1016/j.renene.2020.01.073.

[42] Budt M, Wolf D, Span R, Yan J. A review on compressed air energy storage: Basic principles, past milestones and recent developments. Appl Energy 2016;170:250-68. doi:https://doi.org/10.1016/j.apenergy.2016.02.108.

[43] Kim YM, Kim SJ, Favrat D. Potential and evolution of compressed air energy storage:energy and exergy analyses. . Entropy 2012;14:1501-21.

[44] Chen L, Zheng T, Mei S, Xue X, Liu B, Lu Q. Review and prospect of compressed air energy storage system. J Mod Power Syst Clean Energy n.d.;4. doi:10.1007/s40565016-0240-5.

[45] Zhao P, Gao L, Wang J, Dai Y. Energy efficiency analysis and off-design analysis of two different discharge modes for compressed air energy storage system using axial turbines. Renew Energy 2016;85:1164-77. doi:https://doi.org/10.1016/j.renene.2015.07.095.

[46] Hartmann N, Vöhringer O, Kruck C, Eltrop L. Simulation and analysis of different 
adiabatic Compressed Air Energy Storage plant configurations. Green Energy;

(2)Special Sect from Pap Present 2nd Int Enery 2030 Conf 2012;93:541-8.

doi:http://dx.doi.org/10.1016/j.apenergy.2011.12.007.

[47] Wolf D, Budt M. LTA-CAES - A low-temperature approach to Adiabatic Compressed Air Energy Storage. Appl Energy 125 158-164 2014;125:158-64.

[48] Yang Z, Wang Z, Ran P, Li Z, Ni W. Thermodynamic analysis of a hybrid thermalcompressed air energy storage system for the integration of wind power. Appl Therm Eng 2014;66:519-27. doi:http://dx.doi.org/10.1016/j.applthermaleng.2014.02.043.

[49] Liu J-L, Wang J-H. A comparative research of two adiabatic compressed air energy storage systems. Energy Convers Manag 2016;108:566-78. doi:https://doi.org/10.1016/j.enconman.2015.11.049.

[50] Wei J, Kawaguchi Y, Hirano S, Takeuchi H. Study on a PCM heat storage system for rapid heat supply. Appl Therm Eng 2005;25:2903-20. doi:http://dx.doi.org/10.1016/j.applthermaleng.2005.02.014.

[51] Öztürk HH. Experimental evaluation of energy and exergy efficiency of a seasonal latent heat storage system for greenhouse heating. Energy Convers Manag 2005;46:1523-42. doi:http://dx.doi.org/10.1016/j.enconman.2004.07.001.

[52] Li G, Hwang Y, Radermacher R. Review of cold storage materials for air conditioning application. Int J Refrig 2012;35:2053-77. doi:https://doi.org/10.1016/j.ijrefrig.2012.06.003.

[53] Li G, Hwang Y, Radermacher R, Chun H-H. Review of cold storage materials for subzero applications. Energy 2013;51:1-17. doi:https://doi.org/10.1016/j.energy.2012.12.002.

[54] Xu B, Li P, Chan C. Application of phase change materials for thermal energy storage in concentrated solar thermal power plants: A review to recent developments. Appl Energy 2015;160:286-307. doi:http://dx.doi.org/10.1016/j.apenergy.2015.09.016.

[55] Kuravi S, Trahan J, Goswami DY, Rahman MM, Stefanakos EK. Thermal energy storage technologies and systems for concentrating solar power plants. Prog Energy Combust Sci 2013;39:285-319. doi:http://dx.doi.org/10.1016/j.pecs.2013.02.001.

[56] Aneke M, Wang M. Energy storage technologies and real life applications - A state of the art review. Appl Energy 2016;179:350-77.

[57] Agyenim F, Hewitt N, Eames P, Smyth M. A review of materials, heat transfer and phase change problem formulation for latent heat thermal energy storage systems (LHTESS). Renew Sustain Energy Rev 2010;14:615-28. doi:http://dx.doi.org/10.1016/j.rser.2009.10.015.

[58] Raam Dheep G, Sreekumar A. Influence of nanomaterials on properties of latent heat solar thermal energy storage materials - A review. Energy Convers Manag 2014;83:133-48. doi:https://doi.org/10.1016/j.enconman.2014.03.058.

[59] Liu M, Steven Tay NH, Bell S, Belusko M, Jacob R, Will G, et al. Review on concentrating solar power plants and new developments in high temperature thermal energy storage technologies. Renew Sustain Energy Rev 2016;53:1411-32. doi:https://doi.org/10.1016/j.rser.2015.09.026.

[60] Michels H, Pitz-Paal R. Cascaded latent heat storage for parabolic trough solar power plants. Sol Energy 2007;81:829-37. doi:http://dx.doi.org/10.1016/j.solener.2006.09.008.

[61] Chidiebere Diyoke. Techno-economic analysis of hybrid adiabatic compressed-air and biomass gasification energy storage system for power generation through modelling and simulation. University of Hull, UK, 2018.

[62] Cengel YA. Heat Transfer: A Practical Approach. 2nd Ed edi. Higher Education; 2002.

[63] Yang L, Zhang X, Xu G. Thermal performance of a solar storage packed bed using 
spherical capsules filled with PCM having different melting points. Energy Build 2014;68:639-46. doi:https://doi.org/10.1016/j.enbuild.2013.09.045.

[64] Wakao N, Kagei S. Heat and Mass Transfer in Packed Beds. second. Amsterdam, Netherlands: Gordon and Breach; 1983.

[65] Beek J. Design of packed catalytic reactors . Adv Chem Engng, 1962;3:203-71.

[66] Ismail KAR, Henríquez JR. Numerical and experimental study of spherical capsules packed bed latent heat storage system. Appl Therm Eng 2002;22:1705-16. doi:http://dx.doi.org/10.1016/S1359-4311(02)00080-7.

[67] Benmansour A, Hamdan MA, Bengeuddach A. Experimental and numerical investigation of solid particles thermal energy storage unit. Appl Therm Eng 2006;26:513-8. doi:http://dx.doi.org/10.1016/j.applthermaleng.2005.07.014.

[68] Adebiyi GA. A second-law study on paced bed energy storage systems utilising phase change materials, 113 (1991) 146-156. ASME J Sol Energy Eng 1991;113:146-56.

[69] Buttsworth DR. A Finite Difference Routine for the Solution of Transient One Dimensional Heat Conduction Problems with Curvature and Varying Thermal Properties. vol. TR-2001-01.2001.

[70] Toyama S, Aragaki T, Murase K. Simulation of a multi-effect solar distillator. Desalination, 1983;45:101-8.

[71] Toyama S, Aragaki T, Salah HM, Murase K, and Sando M. Simulation of a multieffect solar still and the static characteristics. J Chem Eng Japan 1987;20(5):473-8.

[72] Ismail KAR, Stuginsky Jr R. A parametric study on possible fixed bed models for pcm and sensible heat storage. Appl Therm Eng 1999;19:757-88. doi:http://dx.doi.org/10.1016/S1359-4311(98)00081-7.

[73] Dincer I. Thermal energy storage systems as a key technology in energy conservation . Int J Energy Res 2002;26:567-88.

[74] Rezaei M, Anisur MR, Mahfuz MH, Kibria MA, Saidur R, Metselaar IHSC. Performance and cost analysis of phase change materials with different melting temperatures in heating systems. Energy 2013;53:173-8. doi:http://dx.doi.org/10.1016/j.energy.2013.02.031.

[75] Ghoshdastidar PS. Computer Simulation of Flow and Heat Tranfer. New Delhi: Tata McGraw Hill; 1998.

[76] Elfeky KE, Ahmed N, Wang Q. Numerical comparison between single PCM and multi-stage PCM based high temperature thermal energy storage for CSP tower plants. Appl Therm Eng 2018. doi:10.1016/j.applthermaleng.2018.04.122.

[77] Aldoss TK, Rahman MM. Comparison between the single-PCM and multi-PCM thermal energy storage design. Energy Convers Manag 2014;83:79-87. doi:http://dx.doi.org/10.1016/j.enconman.2014.03.047. 